\title{
Time Evolution of Estuarine Turbidity Maxima in Well-Mixed, Tidally Dominated Estuaries: The Role of Availability- and Erosion-Limited Conditions
}

\author{
RONALD L. BROUWER AND GEORGE P. SCHRAMKOWSKI \\ Flanders Hydraulics Research, Antwerp, Belgium \\ Yoeri M. DiJKSTRA AND Henk M. SCHUTTElaARS \\ Delft Institute of Applied Mathematics, Delft University of Technology, Delft, Netherlands
}

(Manuscript received 13 September 2017, in final form 17 May 2018)

\begin{abstract}
Using an idealized width-averaged process-based model, the role of a mud pool on the bed and time-varying river discharge on the trapping of fine sediment is systematically investigated. For this purpose, a dynamically and physically motivated description of erodibility is presented, which relates the amount of sediment on the bed to the suspended sediment concentration (SSC). We can distinguish between two states: in the availability-limited state, the SSC is limited by the amount of erodible sediment at the bed. Over time, under constant forcing conditions, the estuary evolves to morphodynamic equilibrium. In the erosion-limited state, there is an abundant amount of sediment at the bed so that sediment pickup occurs at the maximum possible rate. The SSC is then limited by the local hydrodynamic conditions. In this state, the estuary keeps importing sediment, forming an erodible bottom pool that grows in time. These two states can be used to explain the response of an estuary to changing river discharge. Under availability-limited conditions, periods of high river discharge push estuarine turbidity maxima (ETMs) downstream, while drier periods allow ETMs to move upstream. However, when the estuary is in an erosion-limited state during low river discharge, a bottom pool is formed. When the discharge then increases, it takes time to deplete this pool, so that an ETM located over a bottom pool moves with a significant time lag relative to changes in the river discharge. Good qualitative agreement is found between model results and observations in the Scheldt Estuary of surface SSC using a representative year of discharge conditions.
\end{abstract}

\section{Introduction}

The fine sediment distribution in estuaries is strongly influenced by the effects of climate change, such as accelerated sea level rise and intensified river discharge (e.g., Scavia et al. 2002; Robins et al. 2016; Achete et al. 2017), and human interventions, such as land reclamation, channel deepening, and channelization (e.g., de Jonge 1983; Winterwerp and Wang 2013; de Jonge et al. 2014; van Maren et al. 2015). In turn, the sediment distribution impacts the economic and ecological value of the system. For instance, a large (local) suspended sediment concentration (SSC) may contribute to the infilling of navigation channels and/or the siltation of harbors (van Maren et al. 2009), which likely results in an increase of dredging activities. Additionally, regions of high turbidity severely impact (local) light penetration and oxygen levels, resulting

Corresponding author: Ronald L. Brouwer, brouwer.rl@gmail. com in a decrease of primary production (Cloern 1987; Talke et al. 2009; Liu and de Swart 2015).

Variations or changes in the sediment distribution occur at different time scales. For instance, at the decadal time scale channel deepening has caused some European estuaries to undergo a dramatic transition from a state with SSC up to a few hundred milligrams per liter to a hyperturbid state with maximum concentrations of tens of grams per liter. Examples include the Ems Estuary in Germany (Talke et al. 2009; Schuttelaars et al. 2013; de Jonge et al. 2014) and the Loire Estuary in France (Jalón-Rojas et al. 2016). At the annual and seasonal time scale, the river discharge regime induces variations in along-channel sediment distribution, where regions of high SSC, the estuarine turbidity maxima (ETMs), are usually most pronounced during low discharge periods

Publisher's Note: This article was revised on 8 February 2019 to include an addition in the Acknowledgments section that was omitted when originally published. 
(e.g., Castaing and Allen 1981; Woodruff et al. 2001; Lesourd et al. 2003).

Generally, the governing processes that facilitate these variations in sediment distribution consist of interacting vertical and horizontal processes. Vertical processes determine the ability of the water motion to bring into and keep the available sediment in suspension. Horizontal processes control the trapping of fine sediment by either redistributing the sediment already present in the system or by importing it from the sea, the upstream part of the river, or land. The relative importance of the various processes depends on the (time-varying) external forcings and the sediment availability (e.g., Burchard and Baumert 1998). For example, after a wet year in 1998, San Francisco Bay experienced a significant $36 \%$ decrease in SSC, which was hypothesized by Schoellhamer (2011) to be related to a depleted erodible sediment pool. Using a quantitative conceptual model, he confirmed that SSC can suddenly decrease when the threshold from an erosion-limited state to an availability-limited state is crossed, meaning that an erodible sediment pool is depleted. The terms erosionlimited and availability-limited are also referred to as Type II and Type I erosion, respectively (Mehta and Partheniades 1982). Type I erosion (cf. depth-limited, supply-limited, or availability-limited erosion) occurs if SSC is limited by the amount of sediment available for erosion. This occurs when the critical bed shear stress increases with depth into the bed, at the depth where the actual bed shear stress equals the critical bed shear stress. Type II erosion (cf. unlimited erosion) is related to an abundant amount of sediment available for erosion. Thus, SSC is limited by the maximum erosion rate induced by the hydrodynamic conditions.

The main aim of this study is to enhance our understanding of the trapping of fine sediment in estuaries under influence of various processes that act on different time scales. Specifically, we systematically investigate the role of erosion- and availability-limited conditions and timevarying external forcings. For this purpose, several types of process-based models can be employed ranging from exploratory to complex models (Murray 2003). Exploratory, or idealized, models typically aim at reproducing the major phenomena of the system under investigation by only taking into account a limited number of processes that are thought to be important. The key advantages of these models are their excellent ability to quickly investigate the sensitivity of the model outcomes to parameter variations and the possibility to systematically study physical processes in isolation. However, because of idealized nature of these models, the comparison with natural systems has to be qualitative and interpretation of the results requires careful consideration of the effects of the underlying assumptions. Examples of studies on sediment dynamics in estuaries using exploratory models are Burchard and
Baumert (1998), Friedrichs et al. (1998), Chernetsky et al. (2010), de Jonge et al. (2014), Burchard et al. (2013), and Schulz and Umlauf (2016). On the other end of the modeling spectrum, complex models try to reproduce a natural system as closely as possible by implementing all known processes and state-of-the-art parameterizations. These types of models are the method of choice when a high level of accuracy is required. However, they are (presumably) computationally expensive and the results can be more difficult to interpret. Examples of the use of complex models in relation to sediment dynamics in estuaries and coastal seas are Wang (2002), Burchard et al. (2008), and van Maren et al. (2015).

Facilitating the aim of this study, we choose to employ the idealized width-averaged [two-dimensional vertical (2DV)] modeling framework iFlow v2.5 (Dijkstra et al. 2017). It is based on the model by Chernetsky et al. (2010) that was used to study the along-channel distribution of fine sediment in the Ems Estuary, in particular the locations of ETMs. An important assumption in their model is the existence of a morphodynamic equilibrium, that is, a divergence-free, tidally averaged sediment transport. While the approach by Chernetsky et al. (2010) has been successful in determining the physical mechanisms that constitute ETM dynamics in tidal estuaries, it has two drawbacks. First, the model assumes that the sediment concentration scales linearly with the total amount of available sediment, even when sediment is abundant. As a result, the SSC may exceed the carrying capacity of the flow. Second, the morphodynamic equilibrium approach cannot be used for changing external conditions (tides, river discharge), which may vary on time scales from days to years. The approach thus gives the sediment distribution for time-invariant external forcing.

To overcome these two drawbacks, we 1) introduce the concept of dynamic erodibility to set an upper limit for the SSC equal to the carrying capacity of the flow and 2) allow the external conditions and the amount of sediment available in the estuary to change with time. Both concepts are derived from first principles.

This paper is organized as follows. In sections 2 and 3 the adopted model and solution method will be outlined. This includes a brief review of the iFlow model (Dijkstra et al. 2017) and introduces the dynamic erodibility concept and the mass balance of the total amount of sediment in the estuary (both suspended and at the bed). Section 4 is devoted to model results with idealized river discharge time series to explain the concepts of availability- and erosion-limited conditions and to provide an interpretation framework. Subsequently, the sensitivity of the results to the dimensionless erosion parameter, which needs to be calibrated, is discussed in section 5 . The model and interpretation framework are applied to the case study of the Scheldt Estuary in section 6 . Finally, the main results are summarized in section 7. 
TABLE 1. Nomenclature.

\begin{tabular}{|c|c|c|c|}
\hline $\mathcal{F}$ & Subtidal sediment transport $\left(\mathrm{kg} \mathrm{s}^{-1}\right)$ & $P$ & Tidal period (s) \\
\hline $\mathcal{F}_{\text {river }}$ & Sediment input from the river $\left(\mathrm{kg} \mathrm{s}^{-1}\right)$ & $U^{*}$ & Typical value for the horizontal velocity $\left(\mathrm{m} \mathrm{s}^{-1}\right)$ \\
\hline $\mathcal{S}$ & Sediment stock $\left(\mathrm{kg} \mathrm{m}^{-2}\right)$ & $T$ & Advective transport function $\left(\mathrm{kg} \mathrm{m}^{-1} \mathrm{~s}^{-1}\right)$ \\
\hline$\tilde{\mathcal{S}}$ & Dimensionless sediment stock (-) & $Q(t)$ & River discharge $\left(\mathrm{m}^{3} \mathrm{~s}^{-1}\right)$ \\
\hline$\tilde{\mathcal{S}}_{a}$ & $\begin{array}{l}\text { Transition point between a predominantly } \\
\text { sandy and a partly muddy bed (-) }\end{array}$ & $c(x, z, t)$ & Suspended sediment concentration or SSC $\left(\mathrm{g} \mathrm{L}^{-1}\right)$ \\
\hline$\tilde{\mathcal{S}}_{b}$ & $\begin{array}{l}\text { Transition point between a partly muddy and } \\
\text { a muddy bed (-) }\end{array}$ & $c_{t}$ & Temporal derivative of the SSC $\left(\mathrm{g} \mathrm{L}^{-1} \mathrm{~s}^{-1}\right)$ \\
\hline $\mathcal{S}^{*}$ & $\begin{array}{l}\text { Estimate for the amount of sediment in } \\
\text { the stock }\left(\mathrm{kg} \mathrm{m}^{-2}\right)\end{array}$ & $c_{x}$ & Derivative of the SSC w.r.t. $x\left(\mathrm{~g} \mathrm{~L}^{-1} \mathrm{~m}^{-1}\right)$ \\
\hline $\mathcal{S}_{\text {bed }}$ & Amount of erodible sediment at the bed $\left(\mathrm{kg} \mathrm{m}^{-2}\right)$ & $c_{z}$ & Derivative of the SSC w.r.t. $z\left(\mathrm{~g} \mathrm{~L}^{-1} \mathrm{~m}^{-1}\right)$ \\
\hline$\tilde{\mathcal{S}}_{\text {bed }}$ & Relative stock at the bed (-) & $\left\langle c^{0}\right\rangle$ & Leading-order, subtidal SSC $\left(\mathrm{g} \mathrm{L}^{-1}\right)$ \\
\hline$\varepsilon$ & Small expansion parameter: Ratio of $A_{\mathrm{M}_{2}}$ and $H_{0}(-)$ & $c_{\mathrm{M}_{4}}^{0}$ & $\begin{array}{l}\text { Temporal variation of the leading-order, } \mathrm{M}_{4} \text { component of } \\
\text { the SSC }\left(\mathrm{g} \mathrm{L}^{-1}\right)\end{array}$ \\
\hline$\mu$ & $\begin{array}{l}\text { Eigenvalue of the Sturm-Liouville problem regarding } \\
\text { the time evolution of } \mathcal{S}\left(\mathrm{s}^{-1}\right)\end{array}$ & $c_{\mathrm{M}_{8+}}^{0}$ & $\begin{array}{l}\text { Temporal variation of the leading-order SSC at lunar } \\
\text { components } \mathrm{M}_{8+4 n} \text { with } n=0,1, \ldots\left(\mathrm{g} \mathrm{L}^{-1}\right)\end{array}$ \\
\hline$\varphi$ & Relative phase of the $\mathrm{M}_{2}$ and $\mathrm{M}_{4}$ tide $\left(^{\circ}\right)$ & $c_{\mathrm{M}_{2}}^{1}$ & $\begin{array}{l}\text { Temporal variation of the first-order, } \mathrm{M}_{2} \text { component of the } \\
\operatorname{SSC}\left(\mathrm{g} \mathrm{L}^{-1}\right)\end{array}$ \\
\hline$\varphi_{\mathrm{M}_{4 n}}$ & Phases of $\hat{C}_{\mathrm{M}_{4 n}}$ with $n=1,2, \ldots\left(^{\circ}\right)$ & $c_{\mathrm{M}_{6+}}^{1}$ & $\begin{array}{l}\text { Temporal variation of the first-order SSC at lunar } \\
\text { components } \mathrm{M}_{6+4 n} \text { with } n=0,1, \ldots\left(\mathrm{g} \mathrm{L}^{-1}\right)\end{array}$ \\
\hline$\rho_{0}$ & Density of water $\left(\mathrm{kg} \mathrm{m}^{-3}\right)$ & $c^{*}$ & Typical value for the SSC $\left(\mathrm{g} \mathrm{L}^{-1}\right)$ \\
\hline$\rho_{s}$ & Density of sediment $\left(\mathrm{kg} \mathrm{m}^{-3}\right)$ & $\hat{c}^{f}$ & SSC components that scale linearly with $f\left(\mathrm{~g} \mathrm{~L}^{-1}\right)$ \\
\hline$\sigma$ & Angular frequency of the $\mathrm{M}_{2}$ tide $\left(\mathrm{rad} \mathrm{s}^{-1}\right)$ & $\left\langle\hat{c}^{f_{0}}\right\rangle$ & $\begin{array}{l}\text { Subtidal SSC component that scales linearly with } \\
\qquad f\left(\mathrm{~g} \mathrm{~L}^{-1}\right)\end{array}$ \\
\hline$\sigma_{P}$ & Prandtl-Schmidt number (-) & $\hat{c}_{\mathrm{M}_{2}}^{f_{1}}$ & $\begin{array}{l}\text { First-order, } \mathrm{M}_{2} \text { SSC component that scales linearly with } \\
\qquad f\left(\mathrm{~g} \mathrm{~L}^{-1}\right)\end{array}$ \\
\hline$\tau_{b}$ & Dynamic bed shear stress $\left(\mathrm{kg} \mathrm{m}^{-1} \mathrm{~s}^{-2}\right)$ & $\hat{c}_{\mathrm{M}_{4}}^{f_{0}}$ & $\begin{array}{l}\text { Leading-order, } \mathrm{M}_{4} \text { SSC component that scales linearly with } \\
f\left(\mathrm{~g} \mathrm{~L}^{-1}\right)\end{array}$ \\
\hline$\tau_{c}$ & Critical bed shear stress $\left(\mathrm{kg} \mathrm{m}^{-1} \mathrm{~s}^{-2}\right)$ & $\hat{c}^{f x}$ & SSC Components that scale linearly with $f_{x}\left(\mathrm{mg} \mathrm{L}^{-1}\right.$ or kg m$\left.{ }^{-2}\right)$ \\
\hline$\zeta(x, t)$ & Water level (m) & $\hat{c}_{\mathrm{M}_{2}}^{f x_{1}}$ & $\begin{array}{l}\text { First-order, } \mathrm{M}_{2} \text { SSC component that scales linearly with } \\
\quad f_{x}\left(\mathrm{~g} \mathrm{~L}^{-1}\right)\end{array}$ \\
\hline$\zeta_{\mathrm{M}_{2}}^{0}$ & $\begin{array}{l}\text { Leading-order, } \mathrm{M}_{2} \text { component of } \\
\text { the water level }(\mathrm{m})\end{array}$ & $c_{\text {bed }}$ & $\mathrm{SSC}$ at the bed $\left(\mathrm{g} \mathrm{L}^{-1}\right)$ \\
\hline$\left\langle\zeta^{1}\right\rangle$ & First-order, subtidal water level (m) & $c_{\text {sea }}$ & Depth- and tidally averaged SSC at the entrance $\left(\mathrm{g} \mathrm{L}^{-1}\right)$ \\
\hline$\zeta_{\mathrm{M}_{4}}^{1}$ & $\begin{array}{l}\text { First-order, } \mathrm{M}_{4} \text { component of } \\
\text { the water level }(\mathrm{m})\end{array}$ & $f$ & tidally averaged erodibility (-) \\
\hline$A_{\mathrm{M}_{2}}$ & $\mathrm{M}_{2}$ amplitude $(\mathrm{m})$ & $f_{x}$ & Derivative of $f$ w.r.t. $x\left(\mathrm{~m}^{-1}\right)$ \\
\hline$A_{\mathrm{M}_{4}}$ & $\mathrm{M}_{4}$ amplitude $(\mathrm{m})$ & $f^{*}$ & Instantaneous erodibility (-) \\
\hline$A_{v}(x)$ & Vertical eddy viscosity $\left(\mathrm{m}^{2} \mathrm{~s}^{-1}\right)$ & $f_{\text {sea }}$ & Tidally averaged erodibility at the entrance (-) \\
\hline$A_{v 0}$ & Vertical eddy viscosity at the entrance $\left(\mathrm{m} \mathrm{s}^{-1}\right)$ & $f_{\text {meq }}$ & Equilibrium erodibility function (-) \\
\hline$B(x)$ & Estuary width $(\mathrm{km})$ & $f^{\prime}$ & Small perturbation of the erodibility (-) \\
\hline$B^{*}$ & Typical value for the width $(\mathrm{km})$ & $f_{x}^{\prime}$ & Derivative of $f^{\prime}$ w.r.t. $x\left(\mathrm{~m}^{-1}\right)$ \\
\hline$\hat{C}(t)$ & $\begin{array}{l}\text { Local depth-integrated SSC at maximum } \\
\text { erodibility or carrying capacity }\left(\mathrm{mg} \mathrm{L}^{-1} \text { or } \mathrm{kg} \mathrm{m}^{-2}\right)\end{array}$ & $f_{\mu}$ & $\begin{array}{l}\text { Eigenfunction of the Sturm-Liouville problem regarding the } \\
\text { time evolution of } \mathcal{S}(-)\end{array}$ \\
\hline$\langle\hat{C}\rangle$ & Subtidal carrying capacity $\left(\mathrm{kg} \mathrm{m}^{-2}\right)$ & $f_{\text {meq, } 0}$ & Morphodynamic equilibrium solution for $\mathcal{F}_{\text {river }}=0(-)$ \\
\hline$\hat{C}_{\mathrm{M}_{4}}$ & $\begin{array}{l}\text { Maximum, leading-order } \mathrm{M}_{4} \text { deviation } \\
\text { from }\langle\hat{C}\rangle\left(\mathrm{kg} \mathrm{m}^{-2}\right)\end{array}$ & $g$ & Gravitational acceleration $\left(\mathrm{m} \mathrm{s}^{-2}\right)$ \\
\hline$\hat{C}_{\mathrm{M}_{4 n}}$ & $\begin{array}{l}\text { Maximum, even harmonic components of the carrying } \\
\text { capacity with } n=1,2, \ldots\left(\mathrm{kg} \mathrm{m}^{-2}\right)\end{array}$ & $g^{\prime}$ & Reduced gravity $\left(\mathrm{m} \mathrm{s}^{-2}\right)$ \\
\hline$\tilde{C}(t)$ & Dimensionless measure of the carrying capacity $(-)$ & $s_{f}$ & Roughness parameter $\left(\mathrm{m} \mathrm{s}^{-1}\right)$ \\
\hline$D$ & Deposition flux $\left(\mathrm{kg} \mathrm{m}^{-2} \mathrm{~s}^{-1}\right)$ & $t$ & Time (s) \\
\hline E & Erosion flux $\left(\mathrm{kg} \mathrm{m}^{-2} \mathrm{~s}^{-1}\right)$ & $t_{\mathcal{S}}$ & Timescale on which $\mathcal{S}$ varies (s) \\
\hline$\hat{E}$ & Potential erosion flux $\left(\mathrm{kg} \mathrm{m}^{-2} \mathrm{~s}^{-1}\right)$ & $t_{\text {adapt }}$ & Adaptation time scale of the morphodynamic equilibrium (s) \\
\hline$F$ & Diffusive transport function $\left(\mathrm{kg} \mathrm{s}^{-1}\right)$ & $u(x, z, t)$ & Horizontal velocity $\left(\mathrm{m} \mathrm{s}^{-1}\right)$ \\
\hline$H(x)$ & Bed level (m) & $u_{z}$ & Derivative of $u$ w.r.t. $z\left(\mathrm{~s}^{-1}\right)$ \\
\hline$H_{0}$ & Bed level at the entrance $(\mathrm{m})$ & $u_{\mathrm{M}_{2}}^{0}$ & $\begin{array}{l}\text { Temporal variations of the leading-order, } \mathrm{M}_{2} \text { component of } \\
u\left(\mathrm{~m} \mathrm{~s}^{-1}\right)\end{array}$ \\
\hline$H^{*}$ & Typical value for the depth (m) & $\left\langle u^{1}\right\rangle$ & First-order, subtidal component of $u\left(\mathrm{~m} \mathrm{~s}^{-1}\right)$ \\
\hline$K_{h}$ & Horizontal eddy diffusivity $\left(\mathrm{m}^{2} \mathrm{~s}^{-1}\right)$ & $u_{\mathrm{M}_{4}}^{1}$ & Temporal variations of the first-order, $\mathrm{M}_{4}$ component of $u\left(\mathrm{~m} \mathrm{~s}^{-1}\right)$ \\
\hline$K_{v}$ & Vertical eddy diffusivity $\left(\mathrm{m}^{2} \mathrm{~s}^{-1}\right)$ & $w(x, z, t)$ & Vertical velocity $\left(\mathrm{m} \mathrm{s}^{-1}\right)$ \\
\hline$L$ & Estuary length $(\mathrm{m})$ & $w_{s}$ & Settling velocity $\left(\mathrm{mm} \mathrm{s}^{-1}\right)$ \\
\hline$M$ & $\begin{array}{l}\text { Empirical constant or dimensional } \\
\text { erosion parameter }\left(\mathrm{s} \mathrm{m}^{-1}\right)\end{array}$ & $x$ & Along-channel coordinate (m) \\
\hline$\hat{M}$ & Dimensionless erosion parameter (-) & $z$ & Vertical coordinate $(\mathrm{m})$ \\
\hline
\end{tabular}


(a) Side view

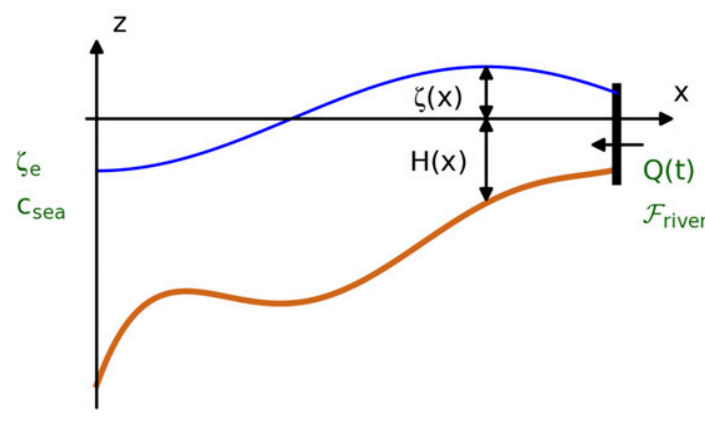

(b) Top view

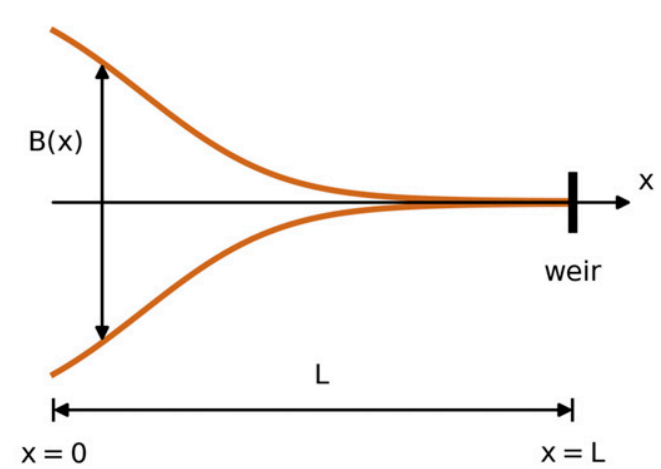

FIG. 1. Geometry of the tidal basin as adopted in the idealized model. The variable names in green are the seaward and landward boundary conditions mentioned in the main text.

\section{Model description}

The trapping of suspended sediments and its evolution on a long time scale will be investigated by extending the width-averaged, semi-analytical approach available in the iFlow modeling framework (Dijkstra et al. 2017). These extensions allow for the temporal evolution of the total sediment stock, which is defined as the sum of the amount of sediment in suspension and in the bottom pool available for erosion, thereby replacing the morphodynamic equilibrium concept with that of dynamic erodibility. In the following sections, the model equations for the water motion and sediment dynamics will be presented, with a special emphasis on the important extensions highlighted above. To aid the model description, a comprehensive overview of the model variables and parameters is presented in Table 1.

\section{a. Model geometry and water motion}

A schematized geometry of a single tidal channel of finite length $L$ is considered, that is, no tributaries are allowed (Fig. 1). The width $B(x)$ and bed level $H(x)$ can vary gradually in the along-channel direction on a length scale comparable to the basin length. The water level $\zeta(x, t)$ horizontal velocity $u(x, z, t)$, and vertical velocity $w(x, z, t)$ follow from solving the Reynolds-averaged and width-averaged shallow water equations. We neglect the effects of Coriolis and assume that density variations are small compared to the average density, allowing for the Boussinesq approximation. We assume a hydrostatic balance and model the baroclinic pressure by a prescribed (i.e., diagnostic) time-independent salinity field that is vertically uniform. The eddy viscosity is assumed to be constant in depth and time, but is allowed to vary in the horizontal direction.

The seaward boundary is situated at $x=0$, where a prescribed tidal water level $\zeta_{e}$ forces the water motion inside the basin. The water motion is only forced by $\mathrm{M}_{2}$ and $\mathrm{M}_{4}$ tidal constituents, resulting in

$$
\zeta_{e}=A_{\mathrm{M}_{2}} \cos (\sigma t)+A_{\mathrm{M}_{4}} \cos (2 \sigma t-\varphi),
$$

where $A_{\mathrm{M}_{2}}, A_{\mathrm{M}_{4}}$, and $\varphi$ denote the amplitudes of the vertical $\mathrm{M}_{2}$ and $\mathrm{M}_{4}$ tide at the entrance and their relative phase, respectively. The quantity $\sigma \sim 1.4 \times 10^{-4} \mathrm{rad} \mathrm{s}^{-1}$ is the angular frequency of the $\mathrm{M}_{2}$ tide.

A weir is located at the landward end $(x=L)$, where a time-dependent river discharge $Q(t)$ is prescribed, such that

$$
B(L) \int_{-H}^{\zeta} u(L, z, t) d z=-\langle Q(t)\rangle .
$$

Here, $\langle$.$\rangle denotes the tidal average and the minus sign$ reflects the fact that the river flow is pointing in the seaward direction. Note that condition (2) allows for a tidally averaged, slowly varying river discharge over the weir.

At the water surface, the usual kinematic boundary condition is adopted in conjunction with the assumption of vanishing shear stress. Moreover, the effect of wind shear stress is neglected. The bed is assumed to be impermeable, while the kinematic bed shear stress depends linearly on the velocity at the bottom (the so-called partial slip condition), that is

$$
A_{v}(x) u_{z}(x,-H, t)=s_{f} u(x,-H, t),
$$

where the quantity $s_{f}$ is the friction parameter and assumed to be constant. Thus, the possible effects of sediment-induced stratification reducing bed shear stress are not incorporated in this model. The subscript $(.)_{z}$ denotes the derivative with respect to height. The vertical eddy viscosity $A_{v}$ is assumed to be vertically 
uniform and is related to the friction parameter and the local bottom depth according to (Dijkstra et al. 2017)

$$
A_{v}(x)=\frac{1}{2} S_{f} H=A_{v 0} \frac{H}{H_{0}},
$$

where $H_{0}$ and $A_{v 0}=s_{f} H_{0} / 2$ denote the bottom depth and vertical viscosity at the entrance, respectively.

\section{b. Sediment concentration}

The width-averaged SSC $c(x, z, t)$ evolves according to the advection-diffusion equation

$$
c_{t}+u c_{x}+w c_{z}=\left(w_{s} c+K_{v} c_{z}\right)_{z}+\frac{1}{B}\left(B K_{h} c_{x}\right)_{x},
$$

where the subscripts $(.)_{x}$ and $(.)_{t}$ denote the derivative with respect to along-channel direction and time, respectively. Furthermore, $w_{s}$ is the settling velocity, which is assumed to be constant in space and time. The vertical diffusivity $K_{v}=A_{v} \sigma_{P}$, with $\sigma_{P}$ the PrandtlSchmidt number taken as 1 for simplicity. The horizontal eddy diffusivity coefficient $K_{h}$ is constant.

At the seaward boundary, a depth and tidally averaged sediment concentration $c_{\text {sea }}$ is prescribed. On the landward side, the tidally averaged sediment transport equals a prescribed fluvial import of sediment $\mathcal{F}_{\text {river }}$ that may vary on a time scale that is long compared to the tidal period.

At the water surface, a zero sediment flux condition is applied. At the bed, the sediment flux follows from the difference between the instantaneous erosion $E$ and deposition $D$. The deposition flux is modeled as $D=w_{s} c_{\text {bed }}$, while the erosion flux reads (Dijkstra et al. 2018)

$$
E= \begin{cases}\hat{E} & \text { if } \mathcal{S}_{\text {bed }}>0, \\ \min \left(\hat{E}, w_{s} c_{\text {bed }}\right) & \text { if } \mathcal{S}_{\text {bed }}=0,\end{cases}
$$

where $c_{\text {bed }}$ is the suspended sediment concentration just above the bed and $\mathcal{S}_{\text {bed }}$ is the amount of erodible sediment at the bed per unit area. The quantity $\hat{E}$ is the potential erosion, that is, the maximum erosion flux given an abundant amount of erodible sediment at the bed. The first condition thus states that the actual erosion rate $E$ is equal to the potential erosion $\hat{E}$ when there is any sediment at the bed available for erosion. The second condition means that the erosion rate can only compensate for the deposition rate, if no sediment is available for erosion at the bed. For notational convenience, Eq. (6) is rewritten as

$$
E=\hat{E} f^{*},
$$

where $f^{*}(x, t)$ denotes the instantaneous relative erodibility, hereinafter denoted as instantaneous erodibility, such that

$$
f^{*}= \begin{cases}1 & \text { if } \mathcal{S}_{\text {bed }}>0, \\ \min \left(1, \frac{w_{s} c_{\text {bed }}}{\hat{E}}\right) & \text { if } \mathcal{S}_{\text {bed }}=0 .\end{cases}
$$

Hence, $f^{*}$ varies between zero (no sediment at the bed and zero deposition) and one (sediment at the bed). The introduction of the instantaneous erodibility is the first novelty compared to earlier work from Chernetsky et al. (2010) and Dijkstra et al. (2017).

The potential erosion $\hat{E}$ can be described by any existing erosion formulation and is usually expressed as $\hat{E}=M\left(\tau_{b}-\tau_{c}\right)$, with $M$ being an empirical constant, $\tau_{b}$ being the dynamic bed shear stress, and $\tau_{c}$ being the critical stress for erosion [see Sanford and Maa (2001) for an extensive discussion]. Among other definitions, in many studies $\tau_{c}$ is a function of erosion depth, representing a continuously increasing critical stress with depth or accounting for various bed layers (Mehta 2014, and references therein). As a consequence, both Type I and Type II erosion can be modeled. The depth dependency of the critical bed shear stress has been applied to several complex 3D numerical models dealing with sediment erodibility, such as the Zuidelijke NoordZee (ZUNO) model (van Kessel et al. 2011), the Community Sediment-Transport Modeling System (CSTMS) model (Warner et al. 2008), and the 3D Hydrodynamic Model for Applications at Regional Scale (MARS3D) model (Mengual et al. 2017). In this study, we take a simpler alternative approach to modeling Type I and Type II erosion. We assume a soft muddy layer (represented by $\mathcal{S}_{\text {bed }}$ ) on top of a sandy bed or consolidated mud layer (hereinafter called "sand"). Correspondingly, $\tau_{c}$ is zero for the muddy layer and $\tau_{c} \gg \tau$ for the sandy bed. Consolidation effects are not taken into account. Type I erosion is represented by the condition that $\mathcal{S}_{\text {bed }}=0$, and thus $0 \leq f^{*}<1$. The condition that $\mathcal{S}_{\text {bed }}>0$, that is, $f^{*}=1$, represents Type II erosion, where the erosion rate is maximal based on the prevailing water motion. Following Huijts et al. (2006) and Chernetsky et al. (2010), we take $M=w_{s} \rho_{s} \hat{M} / \rho_{0} g^{\prime} d_{s}$, resulting in

$$
\hat{E}=\frac{w_{s} \rho_{s} \hat{M}}{\rho_{0} g^{\prime} d_{s}}\left|\tau_{b}(x, t)\right|,
$$

In Eq. (9), $\rho_{s}, \rho_{0}$, and $d_{s}$ denote the density of sediment and water and the grain size, respectively; $g^{\prime}=g\left(\rho_{s}-\rho_{0}\right) / \rho_{0}$ is reduced gravity; and $\hat{M}$ is the dimensionless erosion parameter, which needs to be calibrated. The dynamic bed shear stress $\tau_{b}(x, t)$ is defined as 


$$
\tau_{b}=\rho_{0} A_{v} u_{z}(x,-H, t)=\rho_{0} s_{f} u(x,-H, t),
$$

where the partial slip condition (3) has been used in the last step.

\section{c. Bottom pool evolution}

Contrary to Chernetsky et al. (2010) and Dijkstra et al. (2017), we consider the temporal evolution of the sediment distribution for time-varying external conditions, which is the second novel aspect of this study relative to these previous publications using idealized models. With the time-varying water motion and sediment transport known, we can describe the time evolution of the active bottom pool. To this end, we use $\mathcal{S}_{\text {bed }}$, of which the time evolution is governed by the difference between the (local) deposition $D$ and erosion $E$ that is

$$
B\left(\mathcal{S}_{\text {bed }}\right)_{t}=B(D-E) .
$$

\section{Solution method}

\section{a. Perturbation approach}

Similar to Dijkstra et al. (2017) and Chernetsky et al. (2010), a perturbation approach is used to obtain an approximate solution to the full system of equations. This also enables the identification of relevant processes that underlie the global sediment balance. This approach involves 1) scaling of the governing equations, 2) asymptotic expansion of the physical variables, and 3) harmonic decomposition. Here, these steps are only shortly discussed; for a detailed description, see Dijkstra et al. (2017).

With the scaling method (step 1), the physical variables in the governing equations are made dimensionless using their typical scales. Consequently, the order of magnitude of the various terms in the governing equations is estimated. In the scaled equations a small parameter $\varepsilon$ is identified, which is defined as the ratio of the prescribed amplitude of the $\mathrm{M}_{2}$ water level and the bottom depth at the entrance:

$$
\varepsilon=\frac{A_{\mathrm{M}_{2}}}{H_{0}} \ll 1 .
$$

By relating the magnitude of all terms to $\varepsilon$, the order of magnitude of each term can be determined. It is further assumed that the ratio $A_{\mathrm{M}_{4}} / A_{\mathrm{M}_{2}}$ and the residual velocities due to river discharge and baroclinicity are all of order $\varepsilon$ compared to the $\mathrm{M}_{2}$ tidal velocity. By expanding the physical variables into a series in $\varepsilon$ (step 2), the full set of equations for the water motion and sediment transport is found to reduce to a coupled set of linear equations at different orders of $\varepsilon$, which are much easier to solve than the original problem.

The last step in the perturbation approach is the harmonic decomposition. All physical variables (water level, velocity, sediment concentration) vary both on the long subtidal and short tidal time scale. The leading-order linear equation for the water motion gives the dominant linear $\mathrm{M}_{2}$ tidal flow, while the first-order problem results in subtidal and $\mathrm{M}_{4}$ contributions due to nonlinear interactions of the leading-order tidal signal, the river discharge, density gradients, and the externally prescribed $\mathrm{M}_{4}$ tide. Neglecting contributions of second order and higher, the horizontal velocity and water level can be written in terms of harmonic components as

$$
\begin{aligned}
& u=u_{\mathrm{M}_{2}}^{0}+\left\langle u^{1}\right\rangle+u_{\mathrm{M}_{4}}^{1}, \quad \text { and } \\
& \zeta=\zeta_{\mathrm{M}_{2}}^{0}+\left\langle\zeta^{1}\right\rangle+\zeta_{\mathrm{M}_{4}}^{1},
\end{aligned}
$$

where subscripts denote the tidal constituent and superscripts denote the order of $\varepsilon$. The sediment concentration is written as

$$
c=\left\langle c^{0}\right\rangle+c_{\mathrm{M}_{4}}^{0}+c_{\mathrm{M}_{8+}}^{0}+c_{\mathrm{M}_{2}}^{1}+c_{\mathrm{M}_{6+}}^{1},
$$

where now the residual and $\mathrm{M}_{4}$ contributions are the dominant leading-order quantities, while $c_{\mathrm{M}_{2}}^{1}$ is of order $\varepsilon$. The quantities $c_{\mathrm{M}_{8+}}^{0}$ and $c_{\mathrm{M}_{6+}}^{1}$ denote temporal variations of leading- and first-order sediment concentration at lunar harmonic components $M_{8+4 \mathrm{n}}$ and $M_{6+4 \mathrm{n}}$ $(n=0,1, \ldots)$, respectively. Since these constituents do not result in contributions to the dominant tidally averaged sediment transport, they will be ignored hereinafter.

\section{b. Tidally averaged erodibility}

The sediment concentration depends on the harmonically decomposed instantaneous erodibility $f^{*}(x, t)$ through Eq. (7). In the following, only the tidally averaged effect of $f^{*}(x, t)$ on the long time scale is taken into account. The resulting tidally averaged erodibility, denoted by $f(x, t)$, is defined as a weighted mean (for details, see appendix A),

$$
f=\frac{\left\langle f^{*} \hat{C}(t)\right\rangle}{\langle\hat{C}(t)\rangle},
$$

where $\langle$.$\rangle denotes the tidal average. Parameter \hat{C}(t)$ is the local depth-integrated concentration at maximum instantaneous erodibility (i.e., $f^{*}=1$ ), defined by

$$
\langle\hat{C}\rangle=\left.\int_{-H}^{0} c(x, z, t)\right|_{f *=1} d z .
$$


Hence, $\langle\hat{C}\rangle$ can be seen as the subtidal carrying capacity, that is, the maximum amount of sediment that (on average) can be in suspension locally for given hydraulic conditions. Explicitly, a tidally averaged erodibility $f=1$ means the presence of an erodible, muddy bed layer throughout the entire tidal cycle, while $f<1$ implies that the bed is sandy during at least part of the tidal cycle. Note that we do not account for sand transport or otherwise include sand dynamics in this model.

Now, using the tidally averaged erodibility $f$, we can write the erosion flux, Eq. (6), as

$$
E=\hat{E} f
$$

with $\hat{E}$ given by Eq. (9). ${ }^{1}$ Using this, Eq. (15) can be rewritten as

$$
c(x, z, t)=f \hat{c}^{f}+f_{x} \hat{c}^{f x},
$$

where

$$
\begin{aligned}
\hat{c}^{f} & =\left\langle\hat{c}^{f_{0}}\right\rangle+\hat{c}_{\mathrm{M}_{4}}^{f_{0}}+\hat{c}_{\mathrm{M}_{2}}^{f_{1}}, \\
\hat{c}^{f x} & =\hat{c}_{\mathrm{M}_{2}}^{f x_{1}} .
\end{aligned}
$$

Thus, $\hat{c}^{f}$ denotes SSC components that scale linearly with the erodibility $f$, that is, the subtidal and $\mathrm{M}_{4}$ components and a part of the $\mathrm{M}_{2}$ component. On the other hand, $\hat{c}^{f x}$ denotes SSC components that scale linearly with the longitudinal gradient of the erodibility $f_{x}$, that is, a part of the $\mathrm{M}_{2}$ component. Note that $\hat{c}^{f}$ and $\hat{c}^{f x}$ are completely determined by the water motion and sediment-related parameters. Using these expressions, the subtidal carrying capacity $\langle\hat{C}\rangle$, defined in Eq. (17), can also be expressed as

$$
\langle\hat{C}\rangle=\int_{-H}^{0}\left\langle\hat{c}^{f}\right\rangle d z .
$$

\section{c. Relation between erodibility and sediment stock}

We now have an expression for the concentration in terms of $f$, but have not yet related the tidally averaged $f$ to the amount of sediment at the bed. To do this, we assume that only the upper layer of the bed can exchange sediment with the water column through erosion and

\footnotetext{
${ }^{1}$ The notation used in the erosion flux is slightly different from the one used in Friedrichs et al. (1998) and Chernetsky et al. (2010). In the two papers, the (possibly) spatially varying availability, denoted as $a(x)$, is contained in the reference concentration $c_{\star}$. In the formulation used here, this spatial dependency (now captured by $f$ ) is not absorbed in $\hat{E}$, but made explicit in the factor $f$. Hence, to compare the results between the various papers, one can observe that $\hat{E}=w_{s} c_{\star}$, but only when $a=1$ in Eq. (12) in Chernetsky et al. (2010).
}

deposition, and any change of mass in this layer does not significantly change the bed level $z=-H(x)$. Recall that we define the sediment stock $\mathcal{S}$ as the total tidally averaged amount of sediment in the active bed layer $\mathcal{S}_{\text {bed }}$ and in the water column per unit area, that is

$$
\begin{aligned}
\mathcal{S}(x, t) & =\left\langle\mathcal{S}_{\text {bed }}(x, t)+\int_{-H}^{0} c(x, z, t) d z\right\rangle \\
& =\left\langle\mathcal{S}_{\text {bed }}(x, t)\right\rangle+f(x, t)\langle\hat{C}\rangle .
\end{aligned}
$$

Defining the maximum leading-order deviation from $\langle\hat{C}\rangle[$ Eq. (17)] as

$$
\hat{C}_{\mathrm{M}_{4}}=\left|\int_{-H}^{0} \hat{c}_{\mathrm{M}_{4}}^{f} d z\right|,
$$

the ratio $\hat{C}_{\mathrm{M}_{4}} /\langle\hat{C}\rangle$ is a measure for the relative intertidal variability of the depth-integrated sediment concentration. Using $\langle\hat{C}\rangle$ and $\hat{C}_{\mathrm{M}_{4}}$, an explicit functional relation can be derived between the erodibility $f$ and the dimensionless stock $\tilde{\mathcal{S}}=\mathcal{S} /\langle\hat{C}\rangle$ (for details, see appendix A), resulting in the graphical representation shown in Fig. 2.

From this figure, it follows that for sufficiently small $\tilde{\mathcal{S}}$, such that

$$
\tilde{\mathcal{S}}<\tilde{\mathcal{S}}_{a}=\frac{\langle\hat{C}\rangle-\hat{C}_{\mathrm{M}_{4}}}{\langle\hat{C}\rangle},
$$

the stock $\mathcal{S}$ is smaller than the approximated carrying capacity, that is, the amount of sediment that can be kept in suspension during almost the entire tidal cycle. In this case, the bed shear stress is almost always strong enough to erode all sediment from the active layer, resulting in a predominantly sandy bed. Since we assume that $f$ only varies on the long time scale, this results in the approximation $f=\tilde{\mathcal{S}}$. For higher values of the dimensionless stock $\tilde{\mathcal{S}}$, such that

$$
\tilde{\mathcal{S}}_{a}<\tilde{\mathcal{S}}<\tilde{\mathcal{S}}_{b}=\frac{\langle\hat{C}\rangle+\hat{C}_{\mathrm{M}_{4}}}{\langle\hat{C}\rangle},
$$

there will be mud in the active layer during some parts of the tidal cycle, resulting in a sublinear relation between $f$ and $\tilde{\mathcal{S}}$ [see Eq. (A8) in appendix A]. We denote this situation as a partly muddy bed. For large enough values of the dimensionless stock $\tilde{\mathcal{S}}, \tilde{\mathcal{S}}>\tilde{\mathcal{S}}_{b}$, there will be mud at the bed throughout the entire tidal cycle. This means that the amount of sediment that can be eroded per unit time has reached a maximum and, by definition, $f$ is equal to unity. This situation is considered a muddy bed.

We would like to stress that the dynamic erodibility concept developed here and the availability concept used in Friedrichs et al. (1998) and Chernetsky et al. (2010) are equivalent if the erodibility depends linearly on $\tilde{\mathcal{S}}$. 


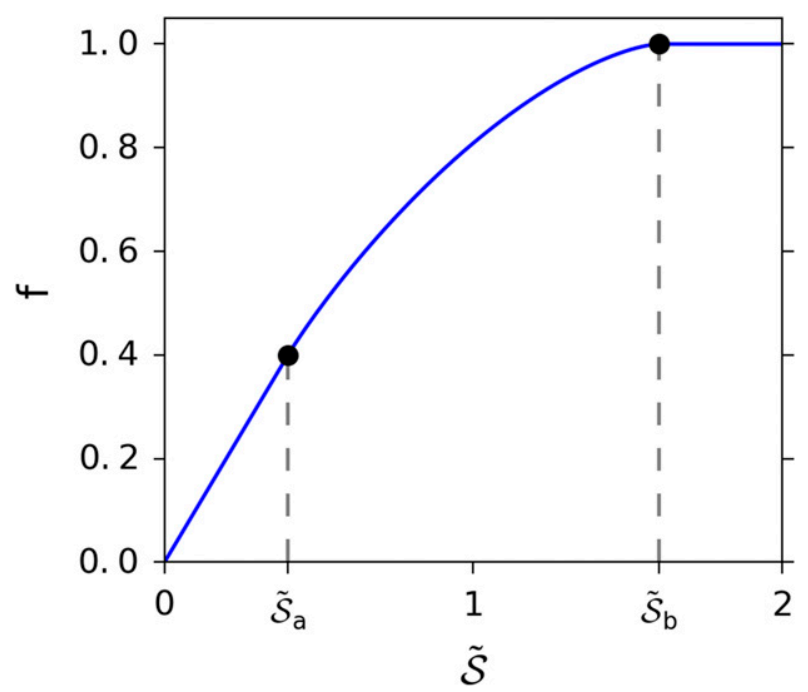

FIG. 2. Graphical representation of the functional relation $f(\tilde{\mathcal{S}})$ for $\hat{C}_{\mathrm{M}_{4}}$ chosen to be $0.6\langle\hat{C}\rangle$. For further information see main text.

Only if abundant amounts of sediments are available do the formulations differ, allowing for erosionlimited behavior when employing the dynamic erodibility formulation.

For future purposes, the notions of availabilitylimited (also called supply-limited, depth-limited, or Type I) and erosion-limited (Type II) circumstances are related to $\tilde{\mathcal{S}}$ here. Availability is limiting if $\tilde{\mathcal{S}}<\tilde{\mathcal{S}}_{b}$. In that case, the amount of sediment in suspension is uniquely related to the amount of sediment in the stock, and this relation exists because the bed is completely sandy during at least some part of the tidal cycle. The situation $\tilde{\mathcal{S}}>\tilde{\mathcal{S}}_{b}$ is referred to as erosion-limited since here the amount of sediment in suspension is at its maximum given the hydraulic conditions (carrying capacity). In the erosion-limited regime, there is no longer a unique relation between erodibility and the stock: all stock values above $\tilde{\mathcal{S}}_{b}$ correspond to $f=1$. Note that $\tilde{\mathcal{S}}$ can vary along a tidal channel, and thus availability-limited and erosion-limited regions can be present simultaneously in an estuary.

\section{d. Subtidal dynamics}

To obtain an explicit expression for the unknown erodibility $f(x, t)$, we consider the time evolution of the total tidally averaged amount of sediment. By integrating the concentration [Eq. (5)] over depth and width and using Eq. (21), the leading-order tidally averaged contribution to the bottom pool evolution [Eq. (11)] can be rewritten in terms of the total stock and the divergence of the subtidal sediment transport $\mathcal{F}$. The fact that the stock evolves on a time scale that is large compared to the $\mathrm{M}_{2}$ tidal period (see appendix B) justifies the use of the subtidal sediment transport. We thus have

$$
B \mathcal{S}_{t}=-\mathcal{F}_{x}
$$

with

$$
\mathcal{F} \equiv-B \frac{d}{d x}\left\langle\int_{-H}^{\zeta}\left(u c-K_{h} c_{x}\right) d z\right\rangle
$$

Since the sediment concentration is related to $f(x, t)$ [see Eq. (19)], Eq. (25) reduces in leading order to

$$
B \mathcal{S}_{t}=-\left(B T f+B F f_{x}\right)_{x},
$$

where

$$
\begin{aligned}
& F=\left\langle\int_{-H}^{0}\left(u \hat{c}_{\mathrm{M}_{2}}^{f x}-K_{h} \hat{c}^{f}\right) d z\right\rangle \\
& T=\left\langle\int_{-H}^{0}\left(u \hat{c}^{f}-K_{h} \hat{c}_{x}^{f}\right) d z+\zeta_{\mathrm{M}_{2}} u_{\mathrm{M}_{2}}(x, 0) \hat{c}^{f}(x, 0)\right\rangle
\end{aligned}
$$

The functions $F$ and $T$ are fully determined by the leadingand first-order water motion (see Chernetsky et al. 2010, section 3.3 and supplementary material; Chernetsky 2012).

The boundary conditions to Eq. (27) are specified in terms of the erodibility $f(x, t)$. At the seaward boundary, the depth- and tidally averaged $\operatorname{SSC} c_{\text {sea }}$ is prescribed, resulting in $f_{\text {sea }}$ such that

$$
f_{\text {sea }} \equiv \frac{H_{0} c_{\text {sea }}}{\left.\langle\hat{C}\rangle\right|_{x=0}} .
$$

At the landward boundary, the total net sediment transport $\mathcal{F}$ equals the fluvial sediment input such that

$$
\left(B T f+B F f_{x}\right)_{\mathrm{x}=L}=-\mathcal{F}_{\text {river }},
$$

where the minus sign on the right-hand side indicates that $\mathcal{F}_{\text {river }}>0$ implies import of sediment from the riverine side.

In addition, an initial condition for $f$ needs to be prescribed, with $f$ being a nonnegative function that is smaller than one and obeys the boundary conditions. Equation (27) is solved for $f$ by applying a backward Euler scheme for time integration, using a secondorder upwind scheme for spatial discretization. This approach has second-order accuracy in space and firstorder accuracy in time. The backward Euler scheme for time integration has been used as it provides better stability compared to second-order integration like Crank-Nicolson. 


\section{Model results}

In this section, we present model results of the tidally averaged sediment distribution for different discharge time series. First, we consider a situation where there is hardly any sediment in the system initially and prescribe both high and low constant river discharges. This enables a thorough analysis of a system's evolution under constant river discharge and under which conditions an equilibrium distribution of suspended sediment can occur. Explicitly, it allows an assessment in terms of the availability- and erosion-limited conditions discussed in section 3c. Next, we consider a discharge time series that smoothly alternates between high and low river discharge and focus on the behavior of the system during the transitions from high to low river discharge and vice versa.

For the experiments, we use parameter values representative for the Scheldt Estuary, which is described in more detail in section $6 a$. The values are listed in Table 2. Additionally, the along-channel profiles for the bed level $H(x)$, width $B(x)$, and salinity $s(x)$ are taken from Dijkstra et al. (2017). We consider $Q=60 \mathrm{~m}^{3} \mathrm{~s}^{-1}$ and $Q=25 \mathrm{~m}^{3} \mathrm{~s}^{-1}$ as representative high and low river discharge, respectively, and assume no influx of fluvial sediment, that is, $\mathcal{F}_{\text {river }}=0$. Finally, we initially set the dimensionless erosion parameter to $\hat{M}=1 \times 10^{-4}$.

\section{a. Constant high river discharge}

We start with a near-empty system by prescribing the initial condition $f_{\text {init }}=f_{\text {sea }}(1-x / L)^{20}$ and calculate the tidally averaged SSC after one year for a constant high river discharge (Fig. 3a). It follows that an ETM has formed around $100 \mathrm{~km}$ from the seaward side with a maximum concentration of approximately $160 \mathrm{mg} \mathrm{L}^{-1}$. The temporal evolution of the SSC toward this final distribution (Fig. 3b) shows that qualitatively the spatial sediment distribution has already formed within 25 days and that equilibrium is reached after approximately 125 days. Dijkstra et al. (2017) found that the dominant physical mechanisms constituting this ETM are the river flow, which transports sediment downstream, and sediment advection and tidal return flow (due to correlations between $\mathrm{M}_{4}$ velocity and $\mathrm{M}_{4}$ concentration) that mainly transport sediment upstream. The accompanying total sediment transport to form the ETM decreases in time to zero until equilibrium is reached (Fig. 3c). The total amount of imported sediment is only distributed throughout the water column (Fig. 3d, blue line), resulting in a depleted bottom pool during the entire simulation (red line). The final along-channel distribution of the erodibility (Fig. 3c, gray dashed line) is qualitatively similar to the distribution of the SSC
TABLE 2. Model parameter values representative for the Scheldt Estuary.

\begin{tabular}{lll}
\hline \hline \multicolumn{1}{c}{ Parameter } & Symbol & \multicolumn{1}{c}{ Value } \\
\hline Length & $L$ & $160 \mathrm{~km}$ \\
$\mathrm{M}_{2}$ amplitude & $A_{\mathrm{M}_{2}}$ & $1.77 \mathrm{~m}$ \\
$\mathrm{M}_{4}$ amplitude & $A_{\mathrm{M}_{4}}$ & $0.14 \mathrm{~m}$ \\
Relative phase & $\varphi$ & $-1.3^{\circ}$ \\
Vertical eddy viscosity & $A_{v 0}$ & $0.0367 \mathrm{~m}^{2} \mathrm{~s}^{-1}$ \\
Vertical eddy diffusivity & $K_{v 0}$ & $0.0367 \mathrm{~m}^{2} \mathrm{~s}^{-1}$ \\
Roughness parameter & $s_{f}$ & $0.0048 \mathrm{~m} \mathrm{~s}^{-1}$ \\
Erosion parameter & $\hat{M}$ & $1 \times 10^{-5}-1 \times 10^{-4}$ \\
Horizontal eddy diffusivity & $K_{h}$ & $100 \mathrm{~m}^{2} \mathrm{~s}^{-1}$ \\
Settling velocity & $w_{s}$ & $2 \mathrm{~mm} \mathrm{~s}^{-1}$ \\
Sediment grain size & $d_{s}$ & $2 \times 10^{-5} \mathrm{~m}$ \\
SSC at the entrance & $c_{\text {sea }}$ & $40 \mathrm{mg} \mathrm{L}^{-1}$ \\
Sediment input from the river & $\mathcal{F}_{\text {river }}$ & 0 \\
\hline
\end{tabular}

(Fig. 3b). The dashed line in Fig. 3c indicates regions where $\tilde{\mathcal{S}}<\tilde{\mathcal{S}}_{a}$, that is, predominantly sandy bed conditions. The maximum value of the along-channel erodibility for each time step, $f_{\max }(t)$, which is usually located in the vicinity of maximum $\left\langle c_{\text {surf }}\right\rangle$, is always smaller than one (Fig. 3d, black line), indicating that the dynamics are availability-limited.

When availability-limited conditions apply throughout the entire estuary (Fig. 3), an equilibrium sediment distribution $\left[\mathcal{S}_{t}=0\right.$; Eq. (25)] occurs if the residual sediment transport is divergence free $\left(\mathcal{F}_{x}=0\right)$. This implies $\mathcal{F}=-\mathcal{F}_{\text {river }}$ by virtue of the up-estuary boundary condition [Eq. (31)]. In the case discussed here, with $\mathcal{F}_{\text {river }}=0$, this means that equilibrium is approached when the net transport across the estuary entrance approaches zero (see Fig. 3c, cyan line). The corresponding equilibrium for $\mathcal{F}_{\text {river }}=0$ is the morphodynamic equilibrium state discussed in Friedrichs et al. (1998) and Chernetsky et al. (2010). It can be proved (appendix C) that for any $\mathcal{F}_{\text {river }}$ a global availability-limited morphodynamic equilibrium is linearly stable, that is, any small perturbation of this equilibrium will disappear over time.

\section{b. Constant low river discharge}

Conducting the same experiment for a constant low river discharge, the final tidally averaged SSC distribution shows two ETMs (Fig. 4a). One ETM is very pronounced and located close to the weir [river kilometer (rkm) 150] with a maximum concentration of approximately $750 \mathrm{mg} \mathrm{L}^{-1}$, and the other ETM is less pronounced, located around rkm 110 with a maximum concentration of approximately $160 \mathrm{mg} \mathrm{L}^{-1}$. The latter ETM appears quite similar to the only ETM in the high river discharge case (see Fig. 3b). However, it turns out that the dominant importing mechanism for this ETM is velocity-depth asymmetry, with sediment advection 

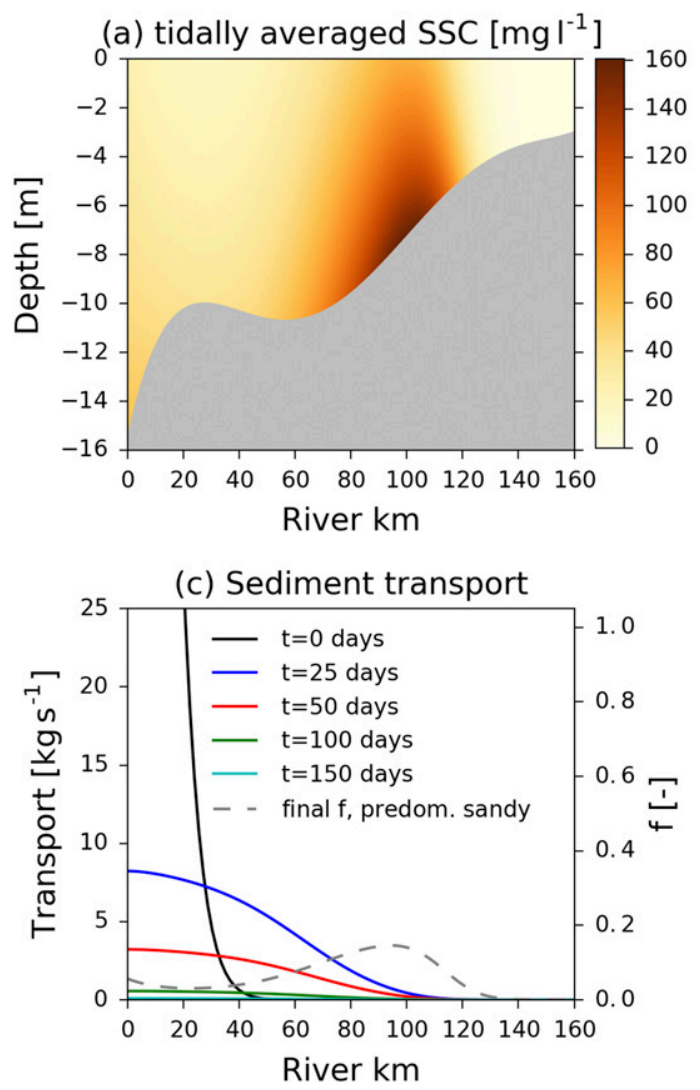

(b) tidally averaged surface SSC

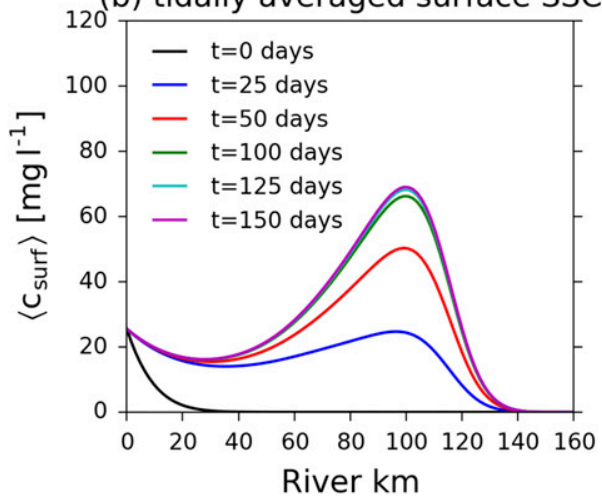

(d) Sediment mass

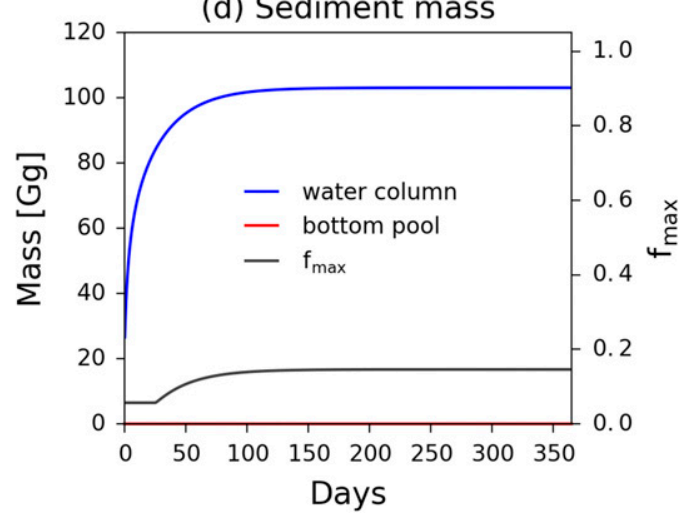

FIG. 3. Temporal evolution of SSC for constant high river discharge: (a) final tidally averaged SSC, (b) temporal evolution of surface SSC, (c) temporal evolution of sediment transport, and (d) temporal evolution of sediment mass. The dashed gray curve in (c) corresponds to regions where $\tilde{\mathcal{S}}<\tilde{\mathcal{S}}_{a}$, that is, predominantly sandy bed conditions.

having a secondary role [see Dijkstra et al. (2017) for a detailed description of the processes]. For the ETM close to the weir, both velocity-depth asymmetry and tidal return flow are important for sediment import. For both ETMs the river flow is still the dominant exporting mechanism. The suspended sediment distribution and mass show a similar evolution as for the high river discharge case and reach equilibrium after approximately 125 days (Fig. 4b, green line, and Fig. 4d, blue line).

In contrast to the high river discharge case, the amount of mass in the bottom pool (Fig. 4d, red line) starts to grow linearly in time after approximately 50 days. The onset of this linear growth coincides with the moment the maximum erodibility reaches a value of 1 (Fig. 4d, black line), indicating that erosion-limited conditions apply. The accumulating bottom pool in the erosion-limited region is supplied by an import of sediment from the seaward boundary that eventually reaches a constant value (Fig. 4c, cyan line). Notice that the final along-channel distribution of $f$ (Fig. 4c, gray line) shows that predominantly sandy bed conditions (dashed gray line) coexist with (partly) muddy bed conditions (solid gray line). Seaward of the erosionlimited region $f<1$ and thus availability-limited conditions apply. Therefore, sediment import becomes constant when an availability-limited equilibrium has set in $\left(\mathcal{F}_{x}=0\right)$. On the landward side of the erosion-limited region $f<1$ and $\mathcal{F}_{\text {river }}=0$, resulting in zero sediment transport. Note that if $\mathcal{F}_{\text {river }}>0$, the bottom pool in the erosion-limited region can additionally be supplied from the landward boundary.

To sum up, similar to the availability-limited equilibrium, the erosion-limited equilibrium is characterized by a tidally averaged suspended sediment distribution that does not vary in time (cf. blue lines in Figs. 3d and 4d). The amount of mass in the bottom pool (cf. red lines in Figs. 3d and 4d), however, grows in time.

\section{c. Transition between high and low river discharge}

To study the transition between high and low river discharge, we impose a discharge time series that smoothly alternates between high $\left(Q=60 \mathrm{~m}^{3} \mathrm{~s}^{-1}\right)$ and 


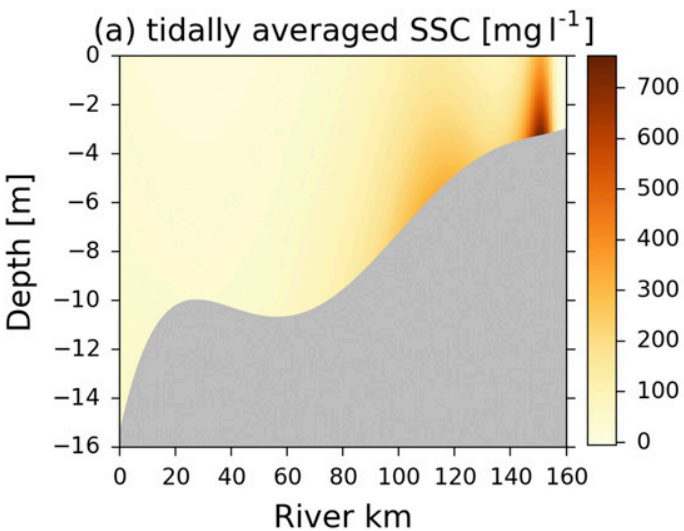

(b) tidally averaged surface SSC

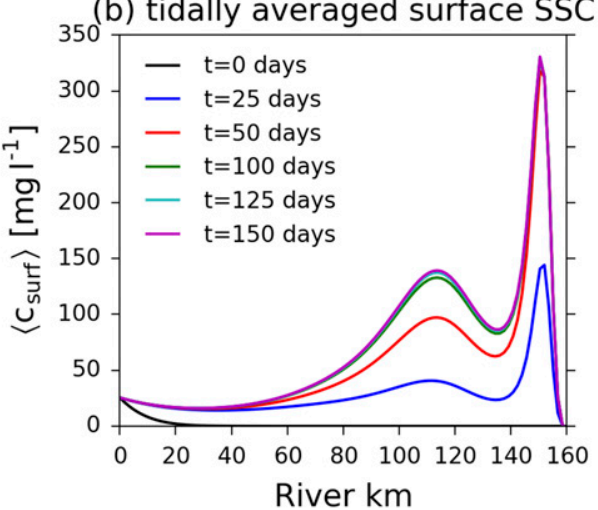

(c) Sediment transport
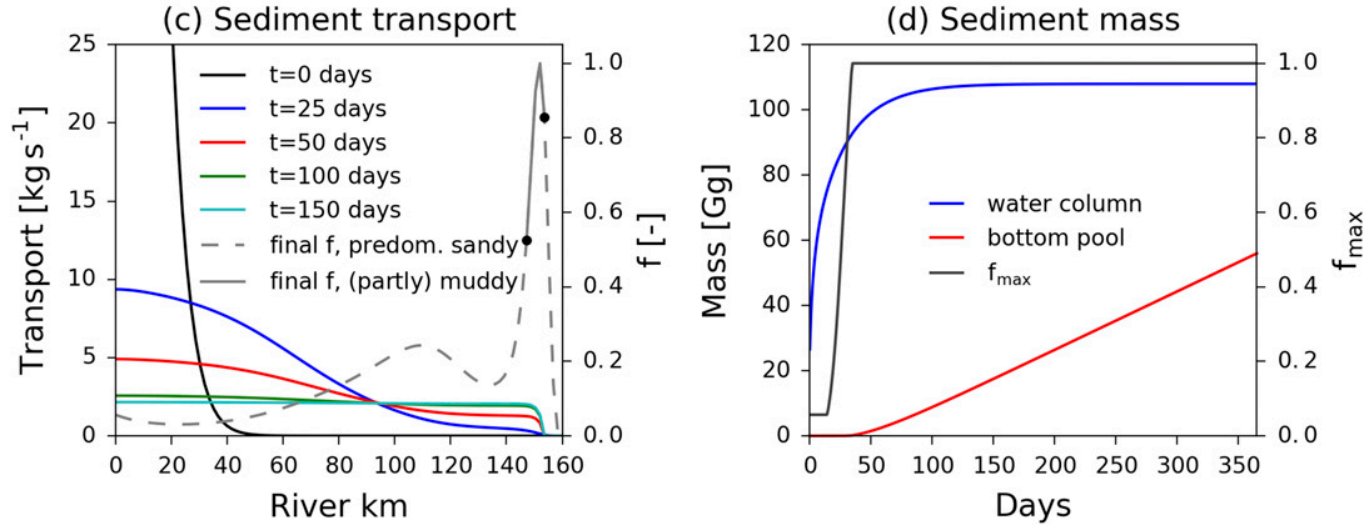

FIG. 4. Temporal evolution of SSC for constant low river discharge. (a) Final tidally averaged SSC, (b) temporal evolution of surface SSC, (c) temporal evolution of sediment transport, and (d) temporal evolution of sediment mass. The dashed gray curve in (c) corresponds to regions where $\tilde{\mathcal{S}}<\tilde{\mathcal{S}}_{a}$, that is, predominantly sandy bed conditions, whereas the solid gray curve corresponds to regions where $\tilde{\mathcal{S}}>\tilde{\mathcal{S}}_{a}$, that is, (partly) muddy bed conditions. The transitions from predominantly sandy to partly muddy conditions are denoted by black dots.

low $\left(Q=25 \mathrm{~m}^{3} \mathrm{~s}^{-1}\right)$ values (see Fig. 5a). The maximum gradients in the river discharge are indicated by the vertical dotted lines.

The simulation starts with the equilibrium SSC distribution corresponding to the high river discharge (see Fig. 3a), which shows a single ETM around rkm 100 (Fig. 5b). After the discharge has dropped below approximately $30 \mathrm{~m}^{3} \mathrm{~s}^{-1}$ around 225 days, a pronounced second ETM emerges close to rkm 150 . When the river discharge transitions back to a high value, initially sediment concentrations significantly increase from rkm 80 to 155 . Subsequently, the SSC values and along-channel distribution evolves back to those corresponding to the high discharge equilibrium.

The maximum along-channel value of the erodibility (Fig. 5c, black line) indicates that, in accordance with Fig. 3d, availability-limited conditions prevail everywhere in the basin at high discharges and no bottom pool has formed (Fig. 5c, red line). At low river discharges, erosionlimited conditions $(f=1)$ apply and we observe the characteristic linear growth of the bottom pool (see also
Fig. 4d). Note that during the phases of constant high and low river discharge, the amount of SSC (Fig. 5c, blue line) reaches a constant value, indicating that both availabilityand erosion-limited equilibrium situations occur.

Remarkably, the total amount of suspended sediment (Fig. 5c, blue line) shows a sharp peak when transitioning from low to high discharge, whereas from high to low discharge this is not the case. This is further explained in Fig. 6. For the transition from high to low discharge (Figs. 6a-e), the local erodibility increases (Fig. 6b) as the river discharge decreases (Fig. 6a). At the same time, the system adapts to the lower discharge by importing sediment over the seaward boundary (Fig. 6c) and depositing it at a second trapping location around $x=150 \mathrm{~km}$ (Fig. 6e). As soon as the new trapping location has reached the maximum possible value of the SSC ( 235 days), and thus an erosion-limited condition sets in, the bottom pool starts to grow (Fig. 6d). After approximately 260 days an erosionlimited equilibrium is reached. 
(a) River discharge time series

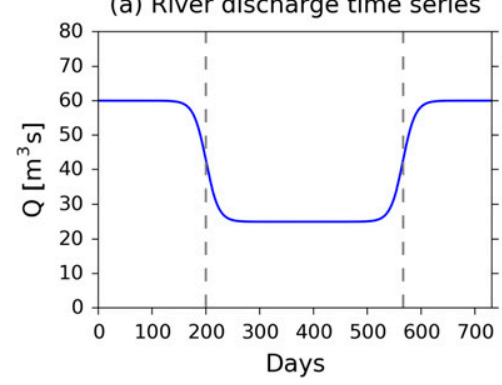

(b) Tidally averaged surface SSC $\left[\mathrm{mgl}^{-1}\right]$

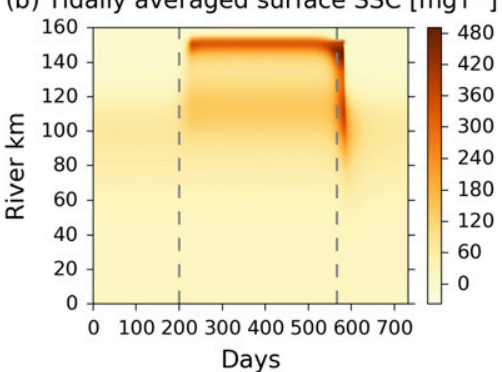

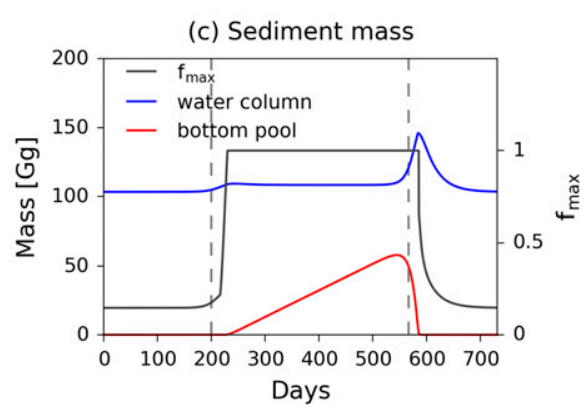

FIG. 5. Temporal evolution of surface SSC and sediment mass for alternating high and low river discharge: (a) discharge time series, (b) tidally averaged surface SSC, and (c) sediment mass.

The transition from low to high river discharge (Figs. 6f-j) shows a different trend. During the period of low river discharge, the bottom pool has grown considerably and peaks around 540 days (cf. Figs. 6d and 6i). After that, as the discharge increases (Fig. 6f), the system adapts by transporting sediment from the bottom pool back to the downstream trapping location (Figs. $6 \mathrm{i}$ and $6 \mathrm{j}$ ). Up to 565 days, this transport to the downstream trapping location is supported by sediment import over the seaward boundary (Fig. 6h). The total amount of suspended sediment peaks around 580 days, which coincides with the moment that the system turns from a state of local erosion limitation to a global state of availability limitation (i.e., $f_{\max }$ drops below unity). At this moment, the bottom pool is depleted and the excess amount of suspended sediment from the upstream trapping location is exported via the downstream trapping location to the sea. In short, it takes time to deplete the bottom pool when transitioning from erosion to availability-limited conditions.

\section{Sensitivity to the erosion parameter $\hat{M}$}

The dimensionless erosion parameter $\hat{M}$, via the potential erosion function $\hat{E}$ [Eq. (7)], determines the amount of sediment that can be kept in suspension under the prevailing hydrodynamic conditions. Consequently, $\hat{M}$ influences the occurrence of regions of erosion limitation: see Fig. 7a. In this figure, for the case of constant low river discharge (section $4 \mathrm{~b}$ and Fig. 4 ), $\hat{M}$ is varied between $0.05 \times 10^{-4}$ and $1.1 \times 10^{-4}$ and shows the corresponding along-channel erodibility $f$ after one year. Confirming the results in Fig. 4, for $\hat{M}=1 \times 10^{-4}$ (upper black dashed line) a single erosion-limited region occurs around rkm 150 (indicated by the area between solid light blue lines). Decreasing $\hat{M}$ ultimately leads to the emergence of a second erosion-limited region around $\mathrm{rkm}$ 100-110. On the other hand, increasing $\hat{M}$ further eventually results in the disappearance of the erosion-limited region around rkm 150 (not shown here). Notice that for most $\hat{M}$ values the largest part of the bed of the estuary is predominantly sandy throughout the entire tidal cycle (area outside of the light blue dashed lines).

The corresponding scaled distribution and maximum value of along-channel tidally averaged surface SSCs are shown in Figs. $7 \mathrm{~b}$ and $7 \mathrm{c}$, respectively. In general, the sediment distribution follows the distribution of the erodibility: high surface SSCs are found where the erodibility approaches unity. Additionally, decreasing $\hat{M}$ values result in decreasing values of the maximum along-channel surface SSC. Note that around a $\hat{M}$ value of $0.2 \times 10^{-4}$ there is a switch in the location where maximum concentrations are found. This is explained by the fact that the SSC is directly linked to the magnitude of the local bed shear stress and the erodibility via the erosion flux $E=\hat{E} f$. As the bed shear stress is higher at the downstream trapping location than at the upstream one (not shown here), the maximum SSC is higher as well for equal $f$. Since the upstream trapping location already is erosion-limited with $f=1$, the downstream trapping location gains importance compared to the upstream trapping location for decreasing $\hat{M}$ values and consequent increasing $f$ values.

The emergence of a second erosion-limited region around rkm $100-110$ for $\hat{M}$ values below approximately $0.1 \times 10^{-4}$ (lower black dashed line) also shows an additional step in the sediment transport (Fig. 8). This additional sediment transport seaward of the mostdownstream trapping location supplies the growth of the local bottom pool at that location. Any further seaward-located erosion-limited region will give rise to similar additional contributions to the sediment transport. All these additions are positive and add up to give either a further reduction of the down-estuary-directed fluvial sediment transport or an import of sediment at the seaward boundary.

\section{Application to the Scheldt Estuary}

In the previous sections, we have used an idealized model for the Scheldt Estuary forced by simplified time 
(a) Transition from high to low discharge

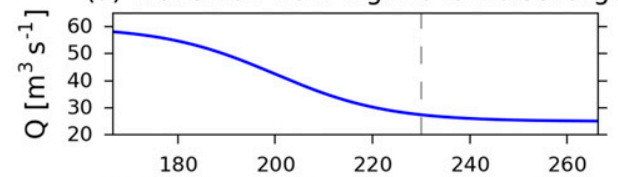

(b) Maximum along-channel erodibility

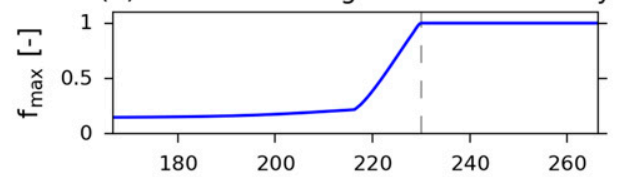

(c) Transport over seaward boundary

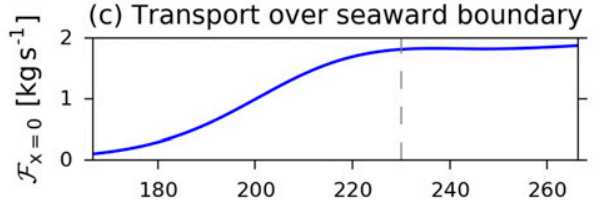

(d) Amount of sediment in bottom pool

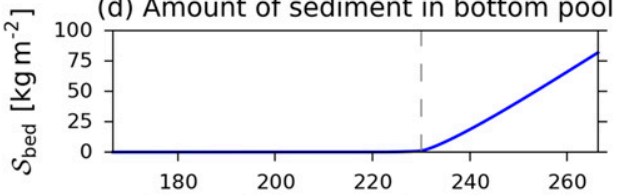

(e) Depth-integrated $\langle\mathrm{c}\rangle\left[\mathrm{kg} \mathrm{m}^{-2}\right]$

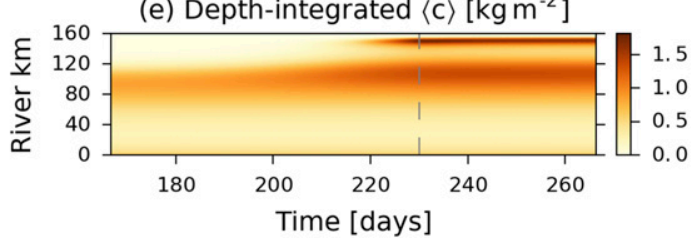

(f) Transition from low to high discharge

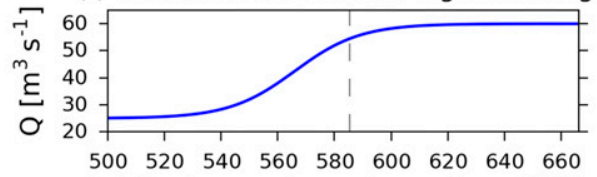

(g) Maximum along-channel erodibility

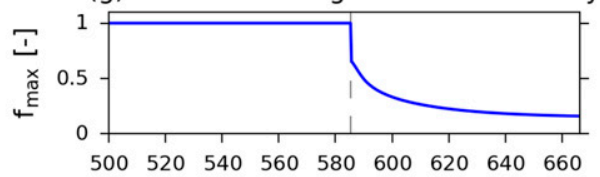

(h) Transport over seaward boundary

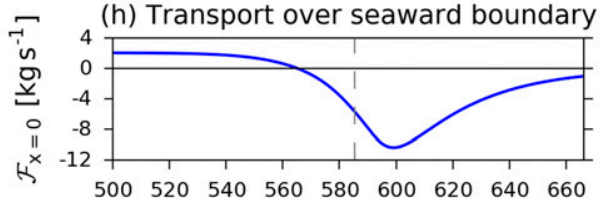

$\tau$ (i) Amount of sediment in bottom pool

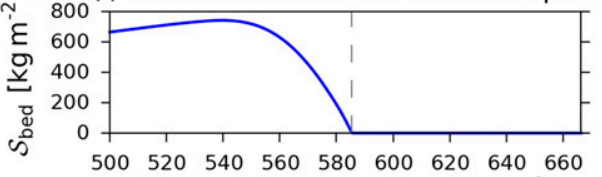

(j) Depth-integrated $\langle\mathrm{c}\rangle\left[\mathrm{kg} \mathrm{m}^{-2}\right]$

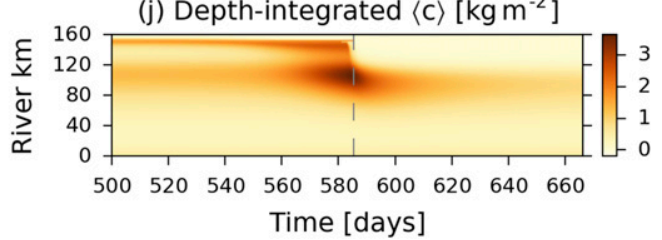

FIG. 6. System transition from high to low discharge (left) and vice versa (right): the (a),(f) river discharge; (b),(g) maximum value of the along-channel erodibility; (c),(h) amount of sediment in the bottom pool; (d),(i) transport over the seaward boundary; and (e),(j) depth-integrated, tidally averaged concentration as a function of along-channel location. The gray dashed line indicates the transition between availability $(f<1)$ and erosion-limited conditions $(f=1)$.

series for the river discharge. The model results give insight into the sediment dynamics and the role of availability- and erosion-limited conditions. Here, we will use this interpretation framework for a realistic river discharge time series that is based on data from the
Scheldt Estuary. Our aim of the comparison is to reproduce trends and orders of magnitude of observed SSC to obtain a better understanding of the underlying physical mechanisms governing the sediment distribution under time-varying forcing. (a) Relative erodibility

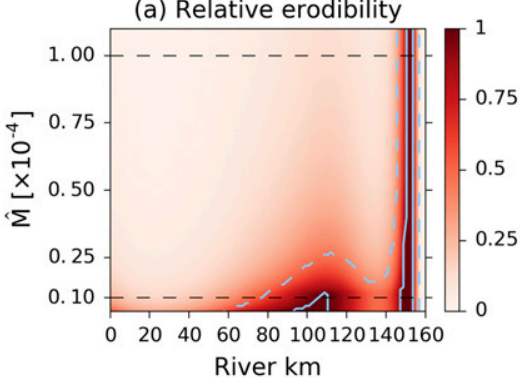

(b) Scaled surface SSC

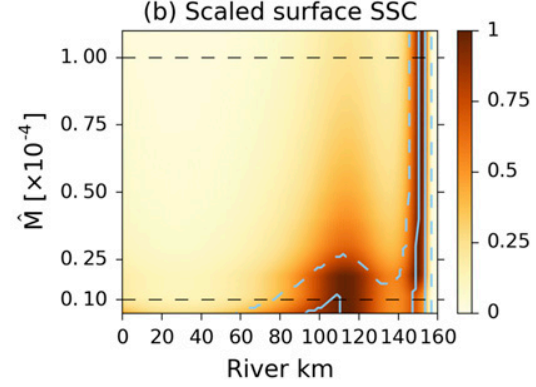

(c) Maximum surface SSC

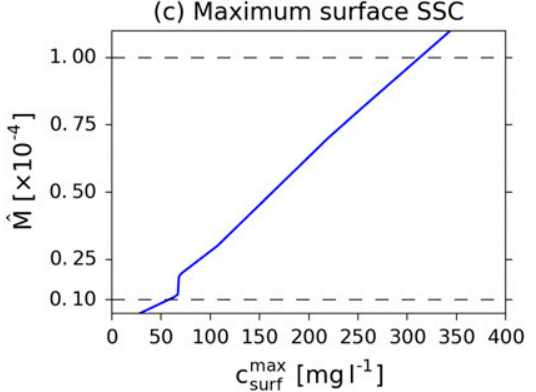

FIG. 7. Sensitivity of model results to $\hat{M}$ for the case of constant low river discharge. The plots show results after one year for (a) the erodibility $f$, (b) the distribution of along-channel surface SSC scaled against the maximum value, and (c) the maximum along-channel surface SSC. The light blue dashed line indicates the transition from a region with a predominantly sandy bed throughout the entire tidal cycle to a region with a muddy bed during parts of the tidal cycle. The light blue solid line indicates the transition from a muddy bed during parts of the tidal cycle to a muddy bed during the entire tidal cycle. 


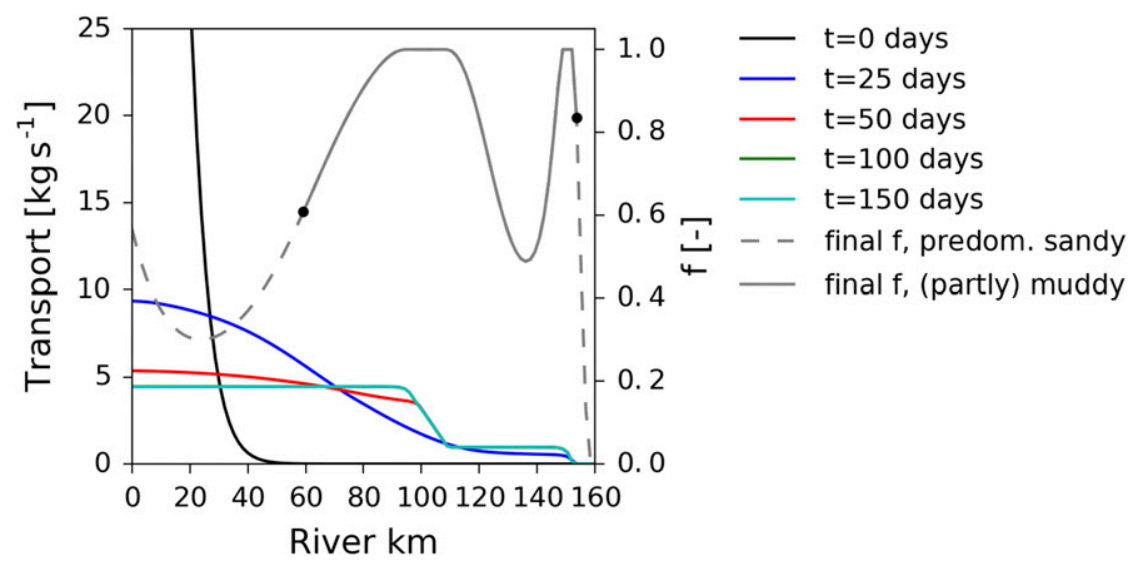

FIG. 8. Temporal evolution of sediment transport (colors) and final spatial distribution of erodibility $f$ (gray) for low river discharge and $\hat{M}=0.1 \times 10^{-4}$. The dashed part of the gray curves correspond to regions where $\tilde{\mathcal{S}}<\tilde{\mathcal{S}}_{a}$, that is, predominantly sandy bed conditions, whereas the solid gray curve corresponds to regions where $\tilde{\mathcal{S}}>\tilde{\mathcal{S}}_{a}$, that is, (partly) muddy bed conditions. The transitions from predominantly sandy to partly muddy conditions are denoted by black dots.

\section{a. The Scheldt Estuary}

The Scheldt Estuary is a macrotidal estuary located on the border between Belgium and the Netherlands (see Fig. 9) and runs from Gentbrugge to Vlissingen. The seaward (Dutch) part is referred to as the Western Scheldt while the Belgian part is called the Sea Scheldt, which is divided in the Upper and Lower Sea Scheldt. The total length $L$ of the estuary is approximately $160 \mathrm{~km}$. At Vlissingen, the estuary is approximately $6 \mathrm{~km}$ wide and has an average depth of $15 \mathrm{~m}$. The mean tidal range at the entrance is about $3.8 \mathrm{~m}$ and increases in the landward direction to reach a maximum of approximately $5.5 \mathrm{~m}$ at Antwerp (rkm 75; Vandenbruwaene et al. 2013). Landward from Antwerp, the tidal range decreases to $\sim 2.7 \mathrm{~m}$, where the estuary has converged to a width and depth of about $50 \mathrm{~m}$ and $3 \mathrm{~m}$, respectively. Here, a weir is situated so that the tidal wave cannot propagate further upstream. At Melle, which is only slightly downstream from the weir, a discharge gauge is located that measures daily averaged runoff values (https://www.waterinfo.be). Median values in the period 1996-2016 range between 10 and $70 \mathrm{~m}^{3} \mathrm{~s}^{-1}$ (Fig. 10), while 25-75 percentile (PCTL) values fluctuate between 5 and $150 \mathrm{~m}^{3} \mathrm{~s}^{-1}$. The saltwater influence typically reaches up to the port of Antwerp and the salinity can be regarded as vertically well mixed.

Near-surface SSC in the Sea Scheldt have been monitored monthly along longitudinal transects from rkm 59 to 150 since 1996 and gathered in the OMES dataset (Maris and Meire 2016). These measurements are taken independent of tidal phase and thus cover many tidal conditions encountered in the Scheldt Estuary. From the data it follows that SSC are moderate, with near-surface concentrations only occasionally and locally (usually between 100 and $140 \mathrm{~km}$ ) exceeding $200 \mathrm{mg} \mathrm{L}^{-1}$ (Fig. 11, blue lines and areas). A dumping area of dredged material is located at rkm 70-75, giving rise to unnatural elevated surface SSC (Fig. 11, gray areas).

The parameter values adopted for the current Scheldt model are taken from Dijkstra et al. (2017) and are summarized in Table 2. Width and depth profiles are obtained by fitting smooth functions through the 2013 data (Coen et al. 2015). Furthermore, it is assumed that the horizontal salinity profile is stationary and depth independent and can be described by a tangent hyperbolic function. The model has been calibrated against $\mathrm{M}_{2}$ and $\mathrm{M}_{4}$ water levels by optimization of a cost function that varies with the hydraulic roughness $s_{f}$, which in turn determines the vertical eddy viscosity $A_{v 0}$ (Dijkstra et al. 2017). Following Coen et al. (2015), the settling velocity of the sediment is $2 \mathrm{~mm} \mathrm{~s}^{-1}$. The depth- and tideaveraged SSC concentration at the entrance, $c_{\text {sea }}$, is set to $40 \mathrm{mg} \mathrm{L}^{-1}$. The sediment input from the river is set to zero, that is, $\mathcal{F}_{\text {river }}=0$. Finally, the dimensionless erosion parameter $\hat{M}$ is chosen to match observations of surface SSC as well as possible, resulting in $\hat{M}=2 \times 10^{-5}$.

\section{b. Results and discussion}

Because SSC data are measured at random moments in the tidal phase only once every month, we define a representative year based on both the median value of daily discharge data and monthly SSC data from 1996 to 2016. Additionally, we use the 25th-75th PCTL values 


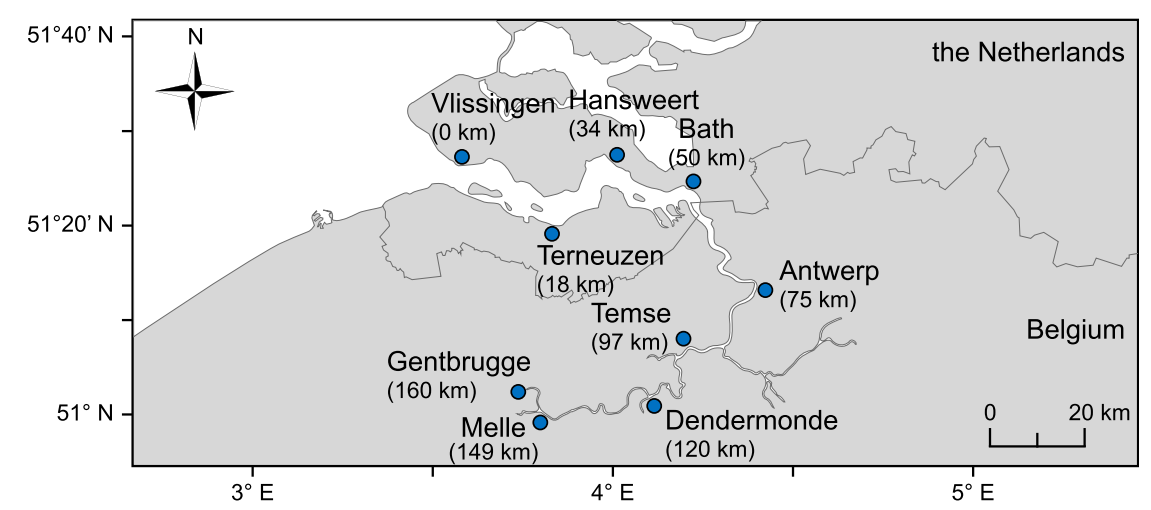

FIG. 9. The Scheldt Estuary.

to highlight the variability of the data. Using the median river discharge time series (Fig. 10a), we start the simulation in morphodynamic equilibrium and run two consecutive years. The computed tidally averaged distribution of surface SSC for the second year and the comparison with observed monthly median SSC from the OMES dataset are depicted in Figs. 10b and 11, respectively. The variability of the tidally averaged model results is denoted by the leading-order $\mathrm{M}_{4}$ concentration [see Eq. (15)]. Apart from the dumping area, the model results match the observations remarkably well. Both the location of the ETM between rkm 100 and 120 and the magnitude of the surface SSC are within reasonable ranges. However, the flushing of the ETM, for example, from January to March, is less well captured by the model. This is, in part, due to the fact that by taking the median values of the river discharge data, major flushing events or periods that push the ETM downstream are filtered out. Additional model runs of individual years with a relatively high river discharge regime (not shown here) revealed that transient behavior of the ETM location is better captured.

During the simulation, two bottom pools are continuously present where the dynamics are erosion-limited (Fig. 12a, red areas). One is located close to the weir, between rkm 140 and 160, and one more downstream
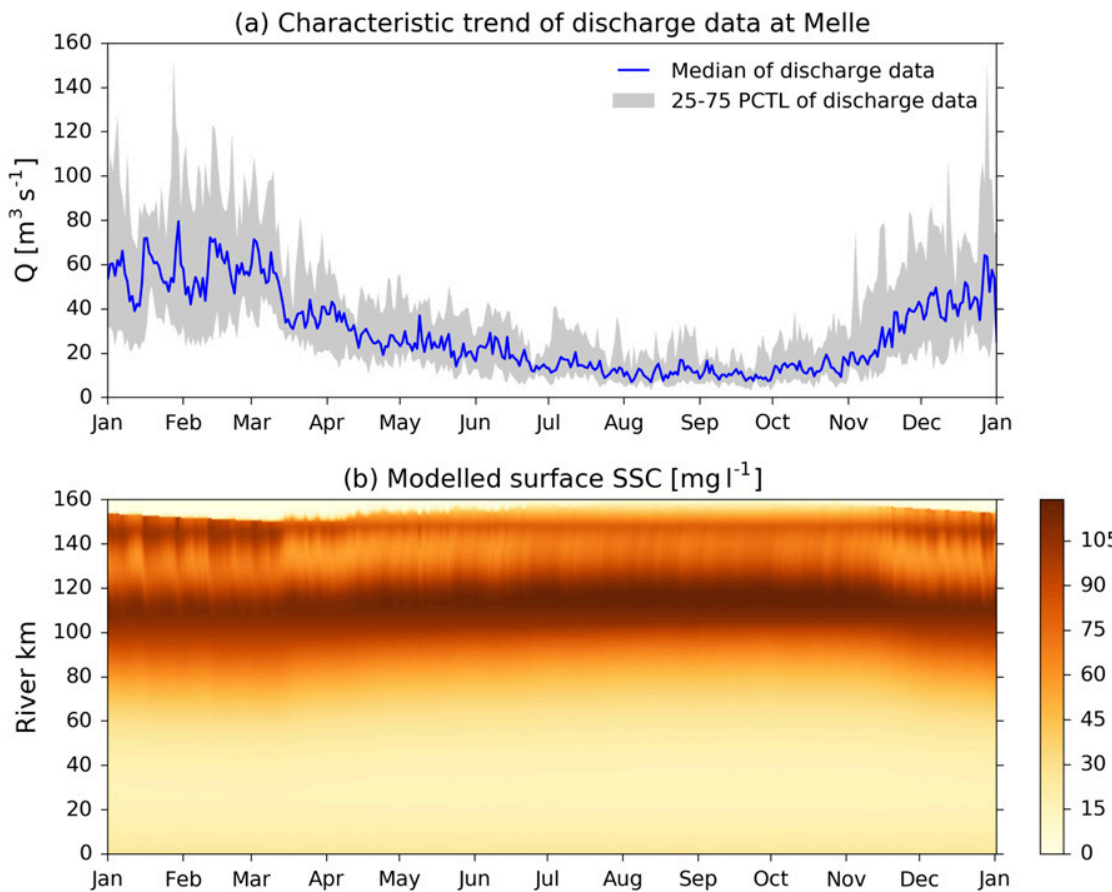

FIG. 10. (a) Median (blue) and 25th-75th PCTL values (gray) for river discharge data at Melle from 1996 to 2016. (b) Computed tidally averaged surface SSC. 

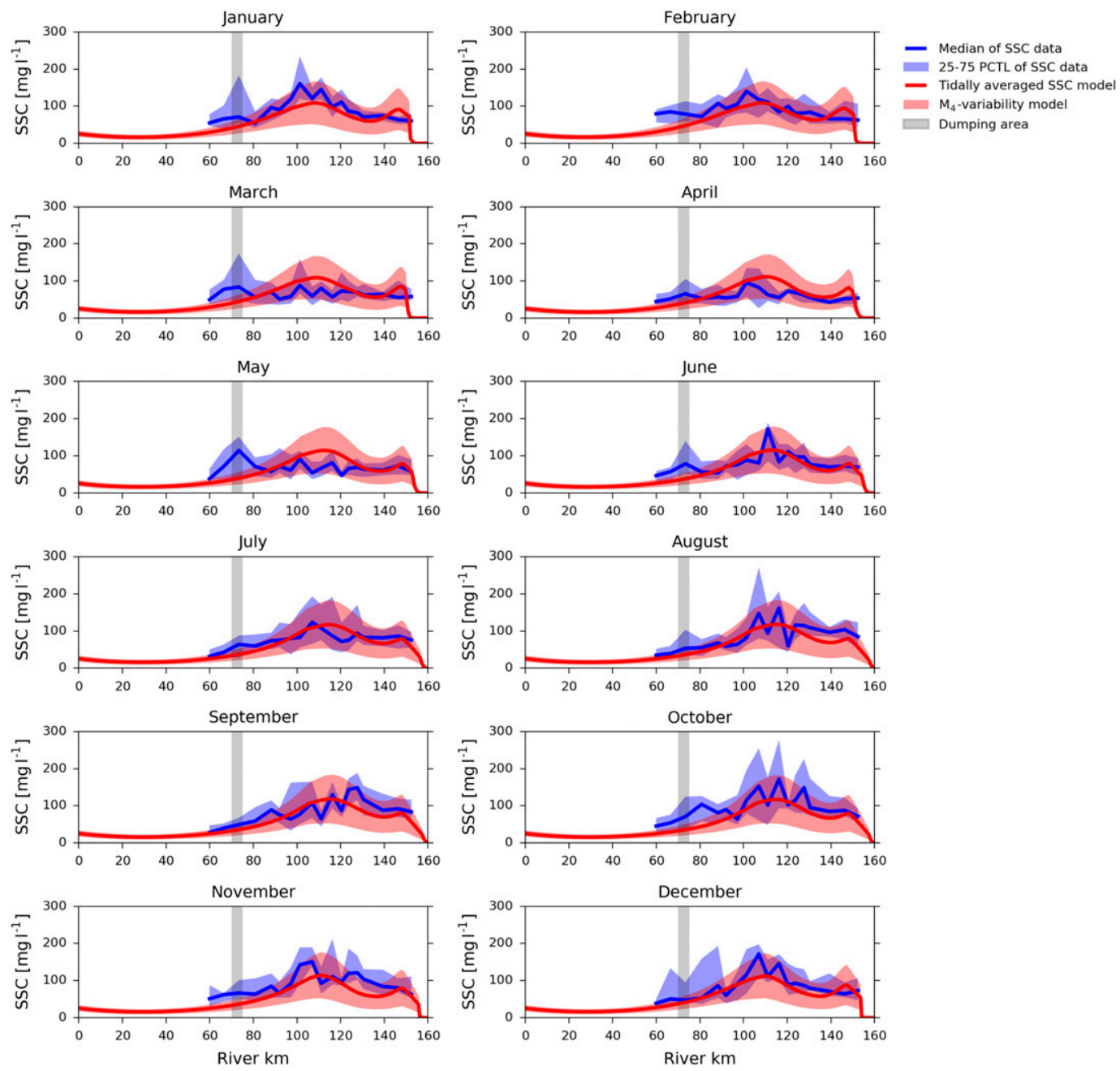

FIG. 11. Comparison of surface SSC data obtained from the OMES dataset and computed surface SSC. The OMES data are presented in blue with the median value of all data from each month in dark blue and the 25th-75th PCTL in light blue. The model results are presented in red with the tidally averaged component in dark red and the $\mathrm{M}_{4}$ variability in light red. The gray area indicates the location of dumping activities.

between rkm 100 and 120. Furthermore, upstream from $\mathrm{rkm} 70$ the bottom composition is muddy during at least part of the tidal cycle. Downstream of rkm 70 the bottom is predominantly sandy.

The total mass of sediment suspended in the water column is almost constant (Fig. 12b, blue line), while the total mass in the two bottom pools fluctuates considerably under the influence of the river discharge (Fig. 12b, red and green line). The bottom pool close to the weir (green line) follows the discharge trend and empties during periods of relatively high river discharge, but never depletes, and fills up during periods of relatively low discharge. In turn, the interior bottom pool (red line) fills up during periods of high river discharge when sediment is pushed downstream and empties during periods of low river discharge, but at a much slower rate.
The mass balance is closed by either an additional import or export of sediment through the seaward boundary (black line), which follows the same trend as the river discharge, that is, import during low discharge and export during high discharge.

\section{Summary and conclusions}

In this paper we have systematically investigated the role of erosion- and availability-limited conditions and time-varying river discharge controlling the trapping of fine sediment in estuaries. To facilitate the investigation we have used the idealized, process-based iFlow modeling framework (Dijkstra et al. 2017), where both vertical and temporal variations of vertical viscosity and diffusivity have been ignored and the bed shear stress is taken to scale 

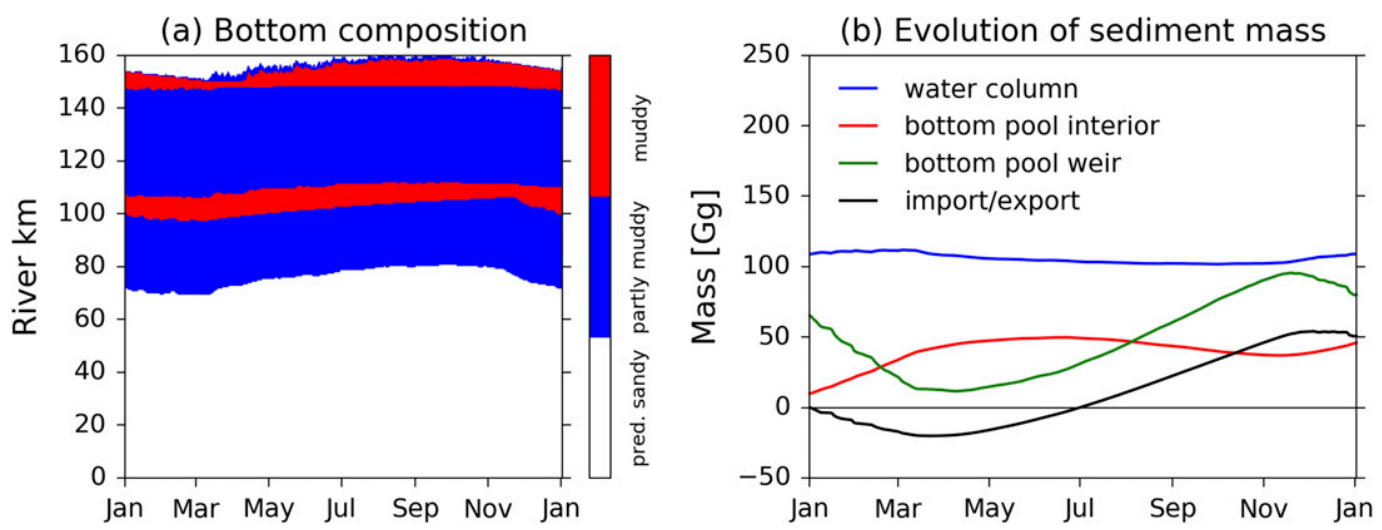

FIG. 12. (a) Bottom composition, distinguishing a predominantly sandy bed (white), a bed that is muddy during at least part of the tidal cycle (blue), and a muddy bed during the entire tidal cycle (red). (b) Evolution of the total sediment mass in the water column (blue), the interior bottom pool (red), the bottom pool at the weir (green), and the import or export relative to the total initial mass (black).

proportional with the near-bed velocity (Lorentz linearization). We have utilized a dynamically and physically motivated description of erodibility that extends the availability concept that was used in similar models by Friedrichs et al. (1998) and Chernetsky et al. (2010). Hereby, the role of a critical shear stress for erosion is not considered.

The erodibility $f(x, t)$ varies on the long subtidal time scale. It is related to the sediment stock $\mathcal{S}$, which measures the total amount of sediment in suspension and material in the active bed layer that is available for erosion. When $\mathcal{S}$ is low, almost all sediment is in suspension. As $\mathcal{S}$ is increased, the bed may become muddy during parts of the tidal cycle. These two situations are referred to as availability-limited conditions, which give concentrations that are limited by the amount of erodible sediment at the bed. In this state, sediment transport is in morphodynamic equilibrium. The SSC in availability-limited conditions tends to, but not necessarily, reach the morphodynamic equilibrium distribution that was already studied in Chernetsky et al. (2010). In the current contribution, it is added that such equilibria are linearly stable. For higher values of $\mathcal{S}$, the bed is muddy throughout the entire tidal cycle so that sediment pickup occurs at the maximum possible rate and erosion-limited conditions apply. The SSC is then limited by the local hydrodynamic conditions, while the mass of the bottom pool increases in time. This situation is also stable in that the SSC does not vary on a subtidal time scale. The growth of the bottom pool requires a net import of sediment through at least one of the boundaries.

In general, during periods of high discharge an ETM is pushed downstream, while during periods of low discharge an ETM moves upstream. For sufficiently low discharges, both availability- and erosion-limited regions will coexist within an estuary. Consequently, in erosion-limited regions an erodible bottom pool will form. When the river discharge increases again, an ETM located at an erosionlimited region maintains its high concentrations until the bottom pool is depleted and thus shows a time lag relative to changes in river discharge. At the same time, the formation of a new turbidity maximum elsewhere in the estuary requires sediment being transported to that location, which might result in an additional sediment import over the system boundaries.

It is further found that the instantaneous horizontal sediment distribution shows good qualitative agreement with the equilibrium distribution. Only when the system transitions from a state of local erosion limitation to global availability limitation is the equilibrium distribution not representative for the instantaneous distribution.

The model is applied to the Scheldt Estuary using a representative year based on median values of a $20-\mathrm{yr}$ discharge and SSC dataset. Despite the adoption of some simplifying assumptions, model results show good qualitative agreement with observations of near-surface SSC. During periods of low river discharge the system tends to import sediment, while during periods of high river discharge it exports sediment.

Acknowledgments. Ronald Brouwer is funded by the VNSC (http://www.vnsc.eu) Agenda for the Future scientific research program through Contract 31096925 and Yoeri Dijkstra is funded through Contract 3110 6170. The authors wish to thank The Flemish Waterway for permission to use the OMES dataset. The authors thank Wouter Vandenbruwaene and Tom Cox for their constructive discussions regarding the OMES data set of the Scheldt Estuary. The authors thank Carl Friedrichs and an anonymous reviewer for their constructive comments. 


\section{APPENDIX A}

\section{Relationship between Erodibility and the Sediment Stock}

In this appendix, a closed functional expression for the erodibility $f(x)$ will be derived. The starting point is Eq. (21), which is repeated for clarity:

$$
\begin{aligned}
\mathcal{S}(x, t) & =\left\langle\mathcal{S}_{\text {bed }}(x, t)+\int_{-H}^{0} c(x, z, t) d z\right\rangle \\
& =\left\langle\mathcal{S}_{\text {bed }}(x, t)\right\rangle+f(x, t)\langle\hat{C}\rangle .
\end{aligned}
$$

Here, $\mathcal{S}_{\text {bed }}$ and $c$ may vary on the short (intertidal) time scale. Furthermore, the stock $\mathcal{S}$ is a conserved quantity on the short time scale, since it can only change by divergence of the horizontal transport $\mathcal{F}$, which evolves on a long time scale (see appendix B). Next, we rewrite the depth integral of the sediment concentration in Eq. (A1) by considering only sediment erosion by the dominant $\mathrm{M}_{2}$ tide:

$$
\int_{-H}^{0} c(x, z, t) d z=f^{*}(t)\left[\langle\hat{C}\rangle+\hat{C}_{\mathrm{M}_{4 n}} \cos \left(2 n \sigma t-\varphi_{\mathrm{M}_{4 n}}\right)\right],
$$

where $f^{*}$ is the instantaneous erodibility, $\langle\hat{C}\rangle$ is the subtidal carrying capacity [Eq. (17)], $\hat{C}_{\mathrm{M}_{4 n}}(n=1,2, \ldots)$ are the even harmonic components of the carrying capacity $\left[\hat{C}_{\mathrm{M}_{4}}\right.$ is defined by Eq. (22)], and $\varphi_{\mathrm{M}_{4 n}}$ are the corresponding phases.

Substituting Eq. (A2) into Eq. (A1) yields an expression for the relative dimensionless stock,

$$
\tilde{\mathcal{S}}=\left\langle\tilde{\mathcal{S}}_{\text {bed }}+f^{*} \tilde{C}(t)\right\rangle,
$$

where $\tilde{\mathcal{S}}_{\text {bed }}=\mathcal{S}_{\text {bed }} /\langle\hat{C}\rangle$ is the relative stock at the bed and

$$
\tilde{C}(t)=1+\frac{\hat{C}_{\mathrm{M}_{4 n}}}{\langle\hat{C}\rangle} \cos \left(2 n \sigma t-\varphi_{\mathrm{M}_{4 n}}\right),
$$

is a nondimensional measure of the maximum amount of sediment in suspension at a given time. Alternatively, $\tilde{C}$ can be interpreted as the dimensionless sediment carrying capacity including temporal settling lag. Note that this capacity has a nonzero minimum, which means that for sufficiently low stock values all sediment will be in suspension for almost the entire tidal cycle. The last term in Eq. (A3) yields, by definition, $f$ by tidal averaging, that is

$$
f=\frac{\left\langle f^{*} \hat{C}(t)\right\rangle}{\langle\hat{C}(t)\rangle}=\left\langle f^{*} \tilde{C}(t)\right\rangle .
$$

To explicitly calculate $f$, we approximate $\tilde{C}(t)$ with only the subtidal and $\mathrm{M}_{4}$ harmonic component (see
Fig. A1, black line). Now, consider the case $\tilde{\mathcal{S}}<\tilde{\mathcal{S}}_{\text {a }}$, for example, the blue line $\tilde{\mathcal{S}}=\tilde{\mathcal{S}}_{1}$ in Fig. A1. The approximated carrying capacity is larger than the stock. Hence, almost all material is in suspension and the erodibility $f^{*}$ follows from

$$
f^{*} \tilde{C}(t) \approx \tilde{\mathcal{S}}
$$

Using Eqs. (A4) and (A5), a near-linear relation between $f$ and $\tilde{\mathcal{S}}$ follows, which we will hereinafter approximate with

$$
f=\tilde{\mathcal{S}} .
$$

We define this situation as a predominantly sandy bed.

On the other hand, if $\tilde{\mathcal{S}}>\tilde{\mathcal{S}}_{\text {b }}$, for example, the green line $\tilde{\mathcal{S}}=\tilde{\mathcal{S}}_{3}$ in Fig. A1, the total amount of sediment is always larger than the carrying capacity. Therefore, $\tilde{\mathcal{S}}_{\text {bed }}$ is positive at any time during the tidal cycle and the erosion is maximum $\left(f^{*}=1\right)$, that is

$$
f=\left\langle f^{*} \tilde{C}(t)\right\rangle=1
$$

This situation is considered as a muddy bed.

In the intermediate regime $\tilde{\mathcal{S}}_{\mathrm{a}}<\tilde{\mathcal{S}}<\tilde{\mathcal{S}}_{\mathrm{b}}$, for example, the red line $\tilde{\mathcal{S}}=\tilde{\mathcal{S}}_{2}$ in Fig. A1, the bed will be muddy only during parts of the tidal cycle, in the intervals $\left(t_{1}, t_{2}\right)$ and $\left(t_{3}, t_{4}\right)$ (red hatched areas), and the mud fraction will increase as $\tilde{\mathcal{S}}$ increases. The tidally averaged erodibility $f$ is then obtained as

$$
f=\frac{1}{P}\left[\int_{\Omega} \tilde{\mathcal{S}} d t+\int_{[0, P] \backslash \Omega} \tilde{C}(t) d t\right],
$$

where $\Omega=\left[t_{1}, t_{2}\right] \cup\left[t_{3}, t_{4}\right]$ and $P$ is the tidal period. The relation $f(\tilde{\mathcal{S}})$ for this intermediate regime is then found to be given by

$$
\begin{aligned}
f(\tilde{\mathcal{S}})= & \frac{1}{2}(1+\tilde{\mathcal{S}})+\frac{1}{\pi} \arcsin \left[\frac{\langle\hat{C}\rangle}{\hat{C}_{\mathrm{M}_{4}}}(\tilde{\mathcal{S}}-1)\right](1-\tilde{\mathcal{S}}) \\
& -\frac{1}{\pi} \sqrt{\left(\frac{\hat{C}_{\mathrm{M}_{4}}}{\langle\hat{C}\rangle}\right)^{2}-(\tilde{\mathcal{S}}-1)^{2}}
\end{aligned}
$$

While Eq. (A8) looks somewhat involved, it merely represents a smooth sublinear increasing transition between a predominantly sandy bed $(f=\tilde{\mathcal{S}})$ and a fully muddy bed $(f=1)$. 


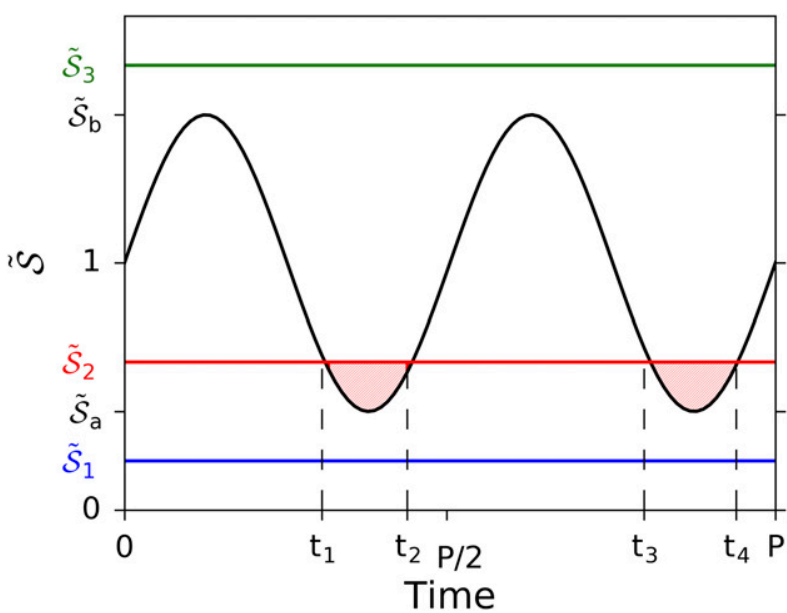

FIG. A1. Graphical representation of Eq. (A3). The black line corresponds to the dimensionless carrying capacity $\tilde{C}(t)$ of the instantaneous hydrodynamic conditions. The three colored horizontal lines indicate three different values of the relative stock.

To summarize, $f(\tilde{\mathcal{S}})$ is given by

$$
f(\tilde{\mathcal{S}})= \begin{cases}\tilde{\mathcal{S}} & \text { if } \tilde{\mathcal{S}} \leq \tilde{\mathcal{S}}_{\mathrm{a}} \\ 1 & \text { if } \tilde{\mathcal{S}} \geq \tilde{\mathcal{S}}_{\mathrm{b}} \\ \text { Eq. (A8) } & \text { otherwise }\end{cases}
$$

It should be noted that $\langle\hat{C}\rangle$ and $\hat{C}_{\mathrm{M}_{4}}$ in general depend on location $x$ and, thus, the transition points $\tilde{\mathcal{S}}_{\mathrm{a}}$ and $\tilde{\mathcal{S}}_{\mathrm{b}}$ between the regimes will vary throughout an estuary.

\section{APPENDIX B}

\section{Estimate of the Sediment Stock Evolution Time Scale}

In this appendix an estimate will be given for the time scale $t_{\mathcal{S}}$ on which the amount of sediment in the stock $\mathcal{S}$ varies. To this end, the net sediment transport $\mathcal{F}$ is estimated as

$$
\mathcal{F} \sim B^{\star} H^{\star} U^{\star} c^{\star}
$$

where $B^{\star}, H^{\star}, U^{\star}$, and $c^{\star}$ denote typical values for width, depth, tidal velocity, and sediment concentration, respectively. The along-channel variation of sediment transport is assumed to occur on the length scale $L$. Using these estimates in Eq. (25) yields

$$
B^{\star} \frac{\mathcal{S}^{\star}}{t_{\mathcal{S}}}=\frac{B^{\star} H^{\star} U^{\star} c^{\star}}{L}
$$

where $\mathcal{S}^{\star}$ is an estimate for the amount of sediment in the stock. Comparing the tidal time scale $P$ (i.e., the tidal period) with the typical time scale $t_{\mathcal{S}}$ at which $\mathcal{S}$ varies, we find that

$$
\frac{P}{t_{\mathcal{S}}}=\frac{P U^{\star}}{L}\left(\frac{H^{\star} c^{\star}}{\mathcal{S}^{\star}}\right)
$$

The term between parentheses is the ratio of depthintegrated concentration to the amount of sediment in the stock, which is typically of order one or less. Using the depth-integrated mass balance, it can be shown that $P U^{\star} / L \sim \varepsilon$ (Schuttelaars and de Swart 2000). It thus follows that

$$
\frac{P}{t_{\mathcal{S}}} \lesssim \varepsilon
$$

and therefore the sediment stock evolves on a time scale that is large compared to the tidal time scale. This justifies the use of tidally averaged sediment transport when considering the evolution of the sediment stock in Eq. (25).

\section{APPENDIX C}

\section{Linear Stability of the Availability-Limited Equilibrium}

Here, it will be shown that the availability-limited equilibrium solution is a stable static solution to Eq. (C1), that is, any small perturbation of this solution will be damped in time. In the availability-limited regime there is a unique (and invertible) relation between $f$ and the amount of sediment in the stock $\mathcal{S}$. The time evolution of $\mathcal{S}$ [Eq. (27)] can then be re-expressed in terms of $f$ alone as

$$
\left(\frac{d f}{d \tilde{\mathcal{S}}}\right)^{-1} f_{t}=-\frac{1}{B\langle\hat{C}\rangle}\left(B T f+B F f_{x}\right)_{x}
$$

An equilibrium sediment distribution $\left(f_{t}=0\right)$ occurs if $\mathcal{F}_{x}$ vanishes throughout the estuary, which implies $\mathcal{F}=-\mathcal{F}_{\text {river }}$ by virtue of the up-estuary condition (31). This is the morphodynamic equilibrium state discussed in Friedrichs et al. (1998) and Chernetsky et al. (2010), albeit with a possibly nonzero tidally averaged sediment transport. The corresponding equilibrium erodibility function, hereinafter denoted by $f_{\text {meq }}$, is then obtained by solving $\mathcal{F}=-\mathcal{F}_{\text {river }}$, which results in

$$
\begin{aligned}
f_{\text {meq }}(x)= & \exp \left(-\int_{0}^{x} \frac{T}{F} d x^{\prime}\right) \\
& \times\left[f_{\text {sea }}-\mathcal{F}_{\text {river }} \int_{0}^{x} \exp \left(\int_{0}^{x^{\prime}} \frac{T}{F} d x^{\prime \prime}\right) \frac{d x^{\prime}}{B F}\right],
\end{aligned}
$$


where $f_{\text {sea }}$ is defined by Eq. (30). With $\mathcal{F}_{\text {river }}=0$, Eq. (C2) is equal to Eq. (S.56) in the supplemental material of Chernetsky et al. (2010).

Next, consider the perturbed solution to Eq. (C1),

$$
f(x, t)=f_{\text {meq }}(x)+f^{\prime}(x, t) .
$$

We then find that any small perturbation $f^{\prime}$ obeys the following time evolution equation:

$$
\begin{aligned}
\left(\frac{d f}{d \tilde{\mathcal{S}}}\right)_{f=f_{\mathrm{meq}}}^{-1} f_{t}^{\prime} & =-\frac{1}{B\langle\hat{C}\rangle}\left(B T f^{\prime}+B F f_{x}^{\prime}\right) \\
& =-\frac{1}{B\langle\hat{C}\rangle}\left[B F f_{\text {meq }, 0}\left(\frac{f^{\prime}}{f_{\text {meq }, 0}}\right)_{x}\right]_{x},
\end{aligned}
$$

where $f_{\text {meq, } 0}$ is the morphodynamic equilibrium solution [Eq. $(\mathrm{C} 2)]$ for the case of zero river input $\left(\mathcal{F}_{\text {river }}=0\right)$. The perturbed boundary conditions [see Eqs. (30) and (31)] are given by

$$
\begin{aligned}
f^{\prime}(x=0) & =0, \quad \text { and } \\
\left(T f^{\prime}+F f_{x}^{\prime}\right)_{x=L} & =0 .
\end{aligned}
$$

Next, we multiply Eq. (C3) with $f^{\prime} / f_{\text {meq, } 0}$, followed by an integration between $x=0$ and $x=L$. Using partial integration along with Eqs. (C4) and (C5) yields the following relationship

$$
\frac{d I}{d t}=\frac{1}{\langle\hat{C}\rangle} \int_{0}^{L} B\left(x^{\prime}\right) F\left(x^{\prime}\right) f_{\text {meq }, 0}\left(x^{\prime}\right)\left[\left(\frac{f^{\prime}}{f_{\text {meq }, 0}}\right)\right]_{x}^{2} d x^{\prime},
$$

where

$$
I=\frac{1}{2} \int_{0}^{L} \frac{B}{f_{\text {meq }, 0}}\left(\frac{d \tilde{\mathcal{S}}}{d f}\right)_{f=f_{\text {meq }}}\left(f^{\prime}\right)^{2} d x^{\prime} .
$$

Note that $I(t)$ is always positive, unless $f^{\prime}$ vanishes everywhere. Also, $F(x)$ is always negative so that the right-hand side of Eq. (C6) is negative, unless again $f^{\prime}$ is identically zero. Hence, it follows from Eq. (C6) that $d I / d t<0$, which implies that $f^{\prime} \rightarrow 0$, and, therefore, any small perturbation of $f_{\text {meq }}$ will damp out and the morphodynamic equilibrium is stable. Note that this argument holds for any relation $f(\tilde{\mathcal{S}})$ that is a monotonically increasing function.

The stability problem can be used to estimate the adaptation time $t_{\text {adapt }}$. To investigate this further, we write the perturbation $f^{\prime}(x, t)$ as

$$
f^{\prime}(x, t)=\exp (-\mu t) f_{\mu}(x) .
$$

We the find that Eq. (C3) can be written as

$$
-\mu B\left(\frac{d \tilde{\mathcal{S}}}{d f}\right)_{\mathrm{f}=\mathrm{f}_{\text {eq }}} f_{\mu}=-\left[B F f_{\text {meq }, 0}\left(\frac{f_{\mu}}{f_{\text {meq }, 0}}\right)\right]_{x},
$$

where $f_{\mu}(x)$ obeys boundary conditions (C4) and (C5). Equation (C8) is a so-called Sturm-Liouville eigenvalue problem. This means that there are infinitely many eigenvalues $\mu$ [and corresponding eigenfunctions $f_{\mu}(x)$ ], which obey Eqs. (C4), (C5), and (C8). Furthermore, the eigenfunctions form a complete set, implying that any arbitrary perturbation $f^{\prime}(x, t)$ is a superposition of these eigenfunctions. Moreover, the eigenvalues are real and can be ordered as follows

$$
\mu_{1}<\mu_{2}<\mu_{3}<\ldots
$$

Consequently, there exists a smallest eigenvalue that, since the equilibrium is stable $\mu_{1}$, must be positive. Any eigenfunction is thus found to decay in time according $\sim \exp (-\mu t)$. From Eq. (C9) it follows that the first eigenfunction $f_{\mu_{1}}$ is the slowest decaying one. Therefore, this eigenmode will dominate the temporal behavior toward the morphodynamic equilibrium. Hence, the inverse of $\mu_{1}$ can be viewed as the time scale on which the equilibrium will settle in, the so-called adaptation time scale $t_{\text {adapt }}$. We thus have

$$
t_{\text {adapt }}=\frac{1}{\mu_{1}} .
$$

\section{REFERENCES}

Achete, F., M. van der Wegen, J. A. Roelvink, and B. Jaffe, 2017: How can climate change and engineered water conveyance affect sediment dynamics in the San Francisco Bay-Delta system? Climatic Change, 142, 375-389, https://doi.org/ 10.1007/s10584-017-1954-8.

Burchard, H., and H. Baumert, 1998: The formation of estuarine turbidity maxima due to density effects in the salt wedge. A hydrodynamic process study. J. Phys. Oceanogr., 28, 309-321, https://doi.org/10.1175/1520-0485(1998) $028<0309$ :TFOETM $>2.0 . \mathrm{CO} ; 2$.

_ G. Flöser, J. V. Staneva, T. H. Badewien, and R. Riethmüller, 2008: Impact of density gradients on net sediment transport into the Wadden Sea. J. Phys. Oceanogr., 38, 566-587, https:// doi.org/10.1175/2007JPO3796.1.

— H. M. Schuttelaars, and W. R. Geyer, 2013: Residual sediment fluxes in weakly-to-periodically stratified estuaries and tidal inlets. J. Phys. Oceanogr., 43, 1841-1861, https://doi.org/ 10.1175/JPO-D-12-0231.1.

Castaing, P., and G. P. Allen, 1981: Mechanisms controlling seaward escape of suspended sediment from the Gironde: A macrotidal estuary in France. Mar. Geol., 40, 101-118, https:// doi.org/10.1016/0025-3227(81)90045-1. 
Chernetsky, A. S., 2012: Trapping of sediment in tidal estuaries. Ph.D. thesis, Delft University of Technology, $162 \mathrm{pp}$.

- H. M. Schuttelaars, and S. A. Talke, 2010: The effect of tidal asymmetry and temporal settling lag on sediment trapping in tidal estuaries. Ocean Dyn., 60, 1219-1241, https://doi.org/ 10.1007/s10236-010-0329-8.

Cloern, J. E., 1987: Turbidity as a control on phytoplankton biomass and productivity in estuaries. Cont. Shelf Res., 7, 13671381, https://doi.org/10.1016/0278-4343(87)90042-2.

Coen, L., B. De Maerschalck, Y. Plancke, T. Verwaest, and F. Mostaert, 2015: Sedimentstrategie Beneden Zeeschelde Deelrapport 1: Opzet, validatie en scenarioberekeningen fase 1 met behulp van een numeriek sedimenttransportmodel. Tech. Rep. WL2015R14_025_1, Flanders Hydraulics Research, 56 pp., http://www.vnsc.eu/uploads/2016/06/wl2016r14025-1-validatieslibmodel.pdf.

de Jonge, V. N., 1983: Relations between annual dredging activities, suspended matter concentrations, and the development of the tidal regime in the Ems Estuary. Can. J. Fish. Aquat. Sci., 40, s289-s300, https://doi.org/10.1139/ f83-290.

, H. M. Schuttelaars, J. E. E. van Beusekom, S. A. Talke, and H. E. de Swart, 2014: The influence of channel deepening on estuarine turbidity levels and dynamics, as exemplified by the Ems estuary. Estuarine Coastal Shelf Sci., 139, 46-59, https:// doi.org/10.1016/j.ecss.2013.12.030.

Dijkstra, Y. M., R. L. Brouwer, H. M. Schuttelaars, and G. P. Schramkowski, 2017: The iFlow modelling framework v2.4: A modular idealized process-based model for flow and transport in estuaries. Geosci. Model Dev., 10, 2691-2713, https://doi.org/10.5194/gmd-10-2691-2017.

—, H. M. Schuttelaars, and J. C. Winterwerp, 2018: The hyperturbid state of the water column in estuaries and rivers: The importance of hindered settling. Ocean Dyn., 68, 377-389, https://doi.org/10.1007/s10236-018-1132-1.

Friedrichs, C. T., B. A. Armbrust, and H. E. de Swart, 1998: Hydrodynamic and equilibrium sediment dynamics of shallow, funnel-shaped tidal estuaries. Physics of Estuaries and Coastal Seas, J. Dronkers and M. Scheffers, Eds., Balkema, 315-328.

Huijts, K. M. H., H. M. Schuttelaars, H. E. de Swart, and A. ValleLevinson, 2006: Lateral entrapment of sediment in tidal estuaries: An idealized model study. J. Geophys. Res., 111, C12016, https://doi.org/10.1029/2006JC003615.

Jalón-Rojas, I., S. Schmidt, A. Sottolichio, and C. Bertier, 2016: Tracking the turbidity maximum zone in the Loire Estuary (France) based on a long-term, high-resolution and highfrequency monitoring network. Cont. Shelf Res., 117, 1-11, https://doi.org/10.1016/j.csr.2016.01.017.

Lesourd, S., P. Lesueur, J. C. Brun-Cottan, S. Garnaud, and N. Poupinet, 2003: Seasonal variations in the characteristics of superficial sediments in a macrotidal estuary (the Seine inlet, France). Estuarine Coastal Shelf Sci., 58, 3-16, https://doi.org/ 10.1016/S0272-7714(02)00340-2.

Liu, B., and H. E. de Swart, 2015: Impact of river discharge on phytoplankton bloom dynamics in eutrophic estuaries: A model study. J. Mar. Syst., 152, 64-74, https://doi.org/10.1016/ j.jmarsys.2015.07.007.

Maris, T., and P. Meire, 2016: OMES rapport 2015: Onderzoek naar de gevolgen van het Sigmaplan, baggeractiviteiten en havenuitbreiding in de Zeeschelde op milieu. Tech. Rep., University of Antwerp, $172 \mathrm{pp}$.
Mehta, A. J., 2014: An Introduction to Hydraulics of Fine Sediment Transport. Advanced Series on Ocean Engineering, Vol. 38, World Scientific, 1039 pp.

- - , and E. Partheniades, 1982: Resuspension of deposited cohesive sediment beds. Coastal Eng. Proc., 18, 15691588.

Mengual, B., P. Le Hir, F. Cayocca, and T. Garlan, 2017: Modelling fine sediment dynamics: Towards a common erosion law for fine sand, mud and mixtures. Water, 9, 564, https://doi.org/ 10.3390/w9080564.

Murray, A. B., 2003: Contrasting the goals, strategies, and predictions associated with simplified numerical models and detailed simulations. Prediction in Geomorphology, Geophys. Monogr., Vol. 135, Amer. Geophys. Union, 151-165, https:// doi.org/10.1029/135GM11.

Robins, P. E., and Coauthors, 2016: Impact of climate change on UK estuaries: A review of past trends and potential projections. Estuarine Coastal Shelf Sci., 169, 119-135, https://oi.org/ 10.1016/j.ecss.2015.12.016.

Sanford, L. P., and J. P.-Y. Maa, 2001: A unified erosion formulation for fine sediments. Mar. Geol., 179, 9-23, https://doi.org/ 10.1016/S0025-3227(01)00201-8.

Scavia, D., and Coauthors, 2002: Climate change impacts on U.S. coastal and marine ecosystems. Estuaries, 25, 149-164, https:// doi.org/10.1007/BF02691304.

Schoellhamer, D. H., 2011: Sudden clearing of estuarine waters upon crossing the threshold from transport to supply regulation of sediment transport as an erodible sediment pool is depleted: San Francisco Bay, 1999. Estuaries Coasts, 34, 885-899, https://doi.org/10.1007/s12237-0119382-x

Schulz, K., and L. Umlauf, 2016: Residual transport of suspended material by tidal straining near sloping topography. J. Phys. Oceanogr., 46, 2083-2102, https://doi.org/10.1175/JPO-D-15-0218.1.

Schuttelaars, H. M., and H. E. de Swart, 2000: Multiple morphodynamic equilibria in tidal embayments. J. Geophys. Res., 105, 24 105-24 118, https://doi.org/10.1029/2000JC900110.

, V. N. de Jonge, and A. S. Chernetsky, 2013: Improving the predictive power when modelling physical effects of human interventions in estuarine systems. Ocean Coastal Manage., 79, 70-82, https://doi.org/10.1016/ j.ocecoaman.2012.05.009.

Talke, S. A., H. E. de Swart, and V. N. de Jonge, 2009: An idealized model and systematic process study of oxygen depletion in highly turbid estuaries. Estuaries Coasts, 32, 602-620, https:// doi.org/10.1007/s12237-009-9171-y.

van Kessel, T., J. Vanlede, and J. de Kok, 2011: Development of a mud transport model for the Scheldt Estuary. Cont. Shelf Res., 31, S165-S181, https://doi.org/10.1016/j. csr.2010.12.006.

van Maren, D. S., J. C. Winterwerp, M. Sas, and J. Vanlede, 2009: The effect of dock length on harbour siltation. Cont. Shelf Res., 29, 1410-1425, https://doi.org/10.1016/j. csr.2009.03.003.

- — - and J. Vroom, 2015: Fine sediment transport into the hyper-turbid lower Ems River: The role of channel deepening and sediment-induced drag reduction. Ocean Dyn., 65, 589605, https://doi.org/10.1007/s10236-015-0821-2.

Vandenbruwaene, W., Y. Plancke, T. Verwaest, and F. Mostaert, 2013: Interestuarine comparison: Hydro-geomorphologyHydro- and geomorphodynamics of the TIDE estuaries Scheldt, Elbe, Weser and Humber. Tech. Rep. WL2013_ 770_62b_rev4_0, Flanders Hydraulic Research, 97 pp., 
http://www.tide-toolbox.eu/pdf/reports/WL2013R770_62b_ rev4_20130220_TIDE_IC_HGM.pdf.

Wang, X. H., 2002: Tide-induced sediment resuspension and the bottom boundary layer in an idealized estuary with a muddy bed. J. Phys. Oceanogr., 32, 3113-3131, https://doi.org/10.1175/ 1520-0485(2002)032<3113:TISRAT >2.0.CO;2.

Warner, J. C., C. R. Sherwood, R. P. Signell, C. K. Harris, and H. G. Arango, 2008: Development of a three-dimensional, regional, coupled wave, current, and sediment-transport model. Comput. Geosci, 34, 1284-1306, https://doi.org/10.1016/ j.cageo.2008.02.012.

Winterwerp, J. C., and Z. B. Wang, 2013: Man-induced regime shifts in small estuaries-I: Theory. Ocean Dyn., 63, 12791292, https://doi.org/10.1007/s10236-013-0662-9.

Woodruff, J. D., W. Geyer, C. K. Sommerfield, and N. W. Driscoll, 2001: Seasonal variation of sediment deposition in the Hudson River estuary. Mar. Geol., 179, 105-119, https://doi.org/ 10.1016/S0025-3227(01)00182-7. 